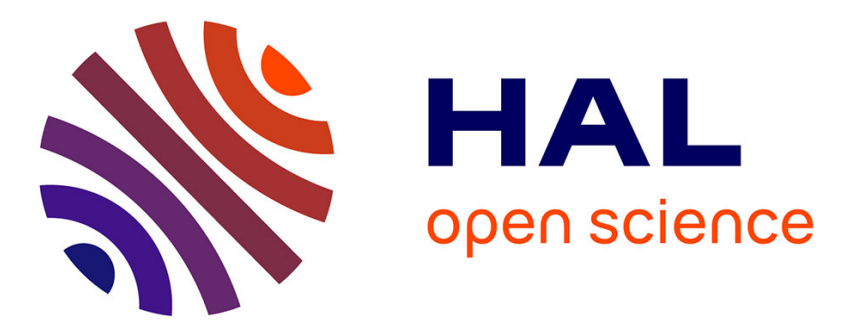

\title{
Giant dune morphologies and dynamics in a deep continental shelf environment: example of the banc du four (Western Brittany, France)
}

Marcaurelio Franzetti, Pascal P. Le Roy, Christophe Delacourt, Thierry Garlan, Romain Cancouët, Alexey Sukhovich, Anne Deschamps

\section{To cite this version:}

Marcaurelio Franzetti, Pascal P. Le Roy, Christophe Delacourt, Thierry Garlan, Romain Cancouët, et al.. Giant dune morphologies and dynamics in a deep continental shelf environment: example of the banc du four (Western Brittany, France). Marine Geology, 2013, 346 (1), pp.17-30. 10.1016/j.margeo.2013.07.014 . insu-00855516

\section{HAL Id: insu-00855516 \\ https://hal-insu.archives-ouvertes.fr/insu-00855516}

Submitted on 29 Aug 2013

HAL is a multi-disciplinary open access archive for the deposit and dissemination of scientific research documents, whether they are published or not. The documents may come from teaching and research institutions in France or abroad, or from public or private research centers.
L'archive ouverte pluridisciplinaire HAL, est destinée au dépôt et à la diffusion de documents scientifiques de niveau recherche, publiés ou non, émanant des établissements d'enseignement et de recherche français ou étrangers, des laboratoires publics ou privés. 


\section{GIANT DUNE MORPHOLOGIES AND DYNAMICS IN A DEEP CONTINENTAL}

SHELF ENVIRONMENT: EXAMPLE OF THE BANC DU FOUR (WESTERN BRITTANY, FRANCE)

Marcaurelio Franzetti ${ }^{1}$, Pascal Le Roy ${ }^{1}$, Christophe Delacourt ${ }^{1}$, Thierry Garlan $^{2}$, Romain Cancouët ${ }^{1}$, Alexey Sukhovich ${ }^{1}$ and Anne Deschamps ${ }^{1}$

${ }^{1}$ Université Européenne de Bretagne Occidentale, UMR-6538 Domaines Océaniques, IUEM/CNRS. place Copernic, 29280 Plouzané, France. E-mail: marcaurelio.franzetti@hotmail.fr, 0033298498717

2 SHOM, DO/HOM/REC-CFuD/Sédimentologie, 13, rue du Chatellier, 29228 Brest, France

\section{Abstract}

The aim of this paper is to improve the knowledge of spatio-temporal variability of very large to giant dunes in deep tide dominated environment. Their growth mechanisms and dynamic evolution still remain in debate and constitute a significant scientific challenge in regard to difficulties to achieve accurate measures of migrations. This motivated the realisation of three recent swath bathymetry surveys across the wide dune field of the Banc $d u$ Four located offshore the western Brittany. The Banc du Four field is composed of more than 500 large dunes exhibiting a great diversity of morphologies ranging from $2 \mathrm{D}$ to $3 \mathrm{D}$ shapes and reaching the largest sizes of such sedimentary structure ever described (wavelength over $1000 \mathrm{~m}$ and height over $30 \mathrm{~m}$ ). The analysis of the entire ensemble of dune parameters offers the opportunity to discuss the relative influence of forcings and the validity of the equations predicting the bedform geometry in shallow waters. Our results show a good height-spacing power law correlation but do not strike the usual statistical regression observed in previous studies. The steeper positive slope of the equation and the outstanding values of the height parameter reveal the complexity of local hydrodynamic regime, interacting with bed load transport and sediment supply. No clear relationship has been observed between asymmetry and size parameters. Water depth cannot be considered as a 
major factor controlling the size of dunes. Otherwise, the vertical sedimentary variation suggests the action of storm waves on dune crests and the horizontal migration rates of dunes in the eastern field of the Banc du Four were found to range from 3 to $20 \mathrm{~m} . \mathrm{yr}^{-1}$. Such velocities were only mentioned before by Van Landeghem et al. (2012) on deep continental shelves (>70 m deep) and attest of the still present morphodynamical equilibrium of the large dunes. Furthermore, as was previously found for similar dunes in the Irish Sea, no power-law relationship between dune migration rates and dune size can be deduced. Similarly, no strong correlation is established between migration rates and the degree of asymmetry. Nevertheless, the dune asymmetry can be used to predict the migration direction. As for dimension parameters, the evolution asymmetry depends on the study area and migration rates. More precisely, when the crest lines of dunes form straight lines and their migration rates remain below 8-10 m. $\mathrm{rr}^{-1}$, the degree of dune asymmetry increases with the migration rate. This trend is reversed for the dunes with higher migration velocities and crests which are sinuous. These results relativize the migratory predictions based on punctual geometrical observations.

\section{Introduction}

Marine dunes are common, sandy bedforms observed on tide-dominated continental shelves. These complex, self-organised systems developed in response to external hydrodynamic parameters (tidal currents, swells, internal waves, storms) and intrinsic sedimentary characteristics (lithology, granularity, supply), as well as shelf morphology and long-term sea level fluctuations (Allen, 1968). As described by Houbolt (1968), Ashley (1990) and Hulscher and Van Den Brink (2001), marine dunes are elongated bedforms perpendicular to the main axis of the prevailing current in a reversing flow regime. Angular variations, reaching up to $20^{\circ}$, are frequently observed. They are different from sandbanks, defined as flow-parallel bedforms or as being slightly oblique $\left(<30^{\circ}\right)$ to the peak tidal flow direction (Le Bot, 2001). Marine dunes are commonly classified by the wavelength $\lambda$, 
allowing for the definition of small $(0.6-5 \mathrm{~m})$, medium $(5-10 \mathrm{~m})$, large $(10-100 \mathrm{~m})$ and very large dunes (>100 m) (Ashley, 1990; Berné et al., 1993). The height, $h$, is another important morphology parameter. Flemming (2000) gives evidence for the existence of an equilibrium geometrical relationship between $\lambda$ and $h$. The corresponding empirical equation is $h=0.0677 \lambda^{0.8098}$ and the author places an upper limit on dune heights at $h_{\max }=0.16 \lambda^{0.84}$. However, despite the compilation of morphology parameters provided by observations of about 1500 dunes in various environments that were used in the previous study, the equation does not take larger bedforms $(\lambda>1000 \mathrm{~m}$ and $\mathrm{h}>20 \mathrm{~m}$ ) from deep (more than $50 \mathrm{~m}$ below sea level, b.s.I.), tidally dominated continental shelves into account (Barrie et al., 2009; Van Landeghem et al., 2009a). For example, the largest dune ( $\mathrm{h}=35.5 \mathrm{~m}$ and $\lambda=435 \mathrm{~m})$ was recently observed in the Irish Sea in water depths of about 90 m L.A.T (Lower Astronomical Tide) (Van Landeghem et al., 2009a).

Other recent studies regarding continental shelves also mentioned the occurrence of deep, large bedforms in the Celtic Sea (Reynaud et al., 1999), the North Sea (Le Bot et al., 2000; Knaapen, 2009), the Irish Sea (Van Landeghem et al., 2009b, 2012), the Australian shelf (Porter-Smith et al., 2004), the China Sea (Zhen Xia et al., 1998) and the western Canadian shelf (Fenster et al., 2006). Despite these numerous examples, their growth mechanisms and dynamic evolution still remain under debate and constitute a long-standing scientific challenge, not only because of the lack of a time series for bathymetric data, but also due to the great spatial variability of sedimentation mechanisms, the absence of current measurements above the seabed and sediment sampling. Furthermore, it is also difficult to compare measurements of the rate of dune migrations provided by different methods with variable accuracy. Nevertheless, the prediction of mobility is vital for assessing the potential risk to offshore installations, as well as for shipping and gravel exploitation (Kenyon and Cooper, 2004). The majority of dynamic studies using swath bathymetry focused on shallow waters (0-30 m L.A.T.), while deeper bedforms were often considered to be moribund, since their dynamics are too low to be reliably detected. In consequence, they were often considered as resulting only from deposits settled during the post-glacial sea-level rise, as in 
the case of the western Approaches sandbanks, synthesised in Reynaud et al. (2003). This motivated the realisation of three recent swath bathymetry surveys conducted across the wide dune field of the Banc du Four, located off the shore of western Brittany (Fig.1). The aim of this paper is to present the results of these surveys and to improve the knowledge of spatio-temporal variability of very large dunes in a deep, tidal-dominated environment. It also offers the opportunity to discuss the relative influence of forcings and the validity of the equations predicting bedform geometry in shallow waters.

\subsection{Migration of dunes}

Dunes are formed in response to the interaction between bedload transport and small bed disturbances associated with turbulent shear (Yalin, 1977; Hulscher, 1996). In the presence of a tidal residual current, sand bodies migrate in the direction of the residual current and acquire asymmetrical shapes during the process of migration (Hulscher and Dohmen-Janssen, 2005). According to one of the migration mechanisms, the material on the stoss side is continuously displaced by the current towards the crest and is then deposited on the lee side. In the case of a strong lee slope (from $30^{\circ}$ ), the crest's sediment descends in the form of an avalanche on the lee side once a certain critical amount is accumulated. As a result, the stoss and lee sides have different slopes, with the stoss side being less steep (Fig. 2). If the dune lee slope remains low, under $14^{\circ}$, it is not sufficient for producing an avalanche and the flow remains attached to dune's lee slope (Best et al., 2004). In consequence, the sediment transport will be caused by water flow rather than by pure grain flow. In the frame of the described migration mechanism, the dune's lee sides should be oriented in the direction of migration and the degree of asymmetry should allow for the deduction of the residual flow direction. Moreover, Knaapen (2005) has shown that the degree of asymmetry increases with the migration velocity; therefore, the dune shapes reflect the hydrodynamic conditions. According to several authors such as Kleinhans (2004), dunes with linear crests (2D) correspond to slower migration velocities and undulatory, sinuous to barchanoid dunes (3D) are characterised by higher migration velocities. In addition, when the 
current cannot set all the sedimentary particles in motion, or when there is a sand deficit, dunes are mostly barchanoid-shaped, whereas they have a linear shape when the current is saturated by sediments (Garlan, 2007). Nevertheless, recently repeated seasonal to annual surveys of the dune fields in the Irish Sea have shown that a considerable amount of sedimentary waves migrate counter-intuitively in the direction of their gentle stoss slopes. Thus, this raises questions regarding the validity of geometry-based predictive modelling (Van Landeghem et al., 2012). As suggested by the authors, these results could be attributed to crestal flexing, bi-directional migration of superimposed sandwaves and other internal feedback between neighbouring sedimentary structures. Less importantly, it could also be caused by a lack of surveying. In any event, these results need to be complemented by additional observations in similar environments to confirm the existence of reversed dune migration. Residual migration reflects the net bedload transport in the long term (Stride, 1963). It is usually reported that sandwaves generated by tidal currents migrate in the direction of the residual steady current (downstream). However, upstream-migrating sandwaves have also been described, and Besio et al. (2004) have shown that upstream/downstream propagation is mainly controlled by the relative strength of the residual current with respect to the amplitude of the quarter-diurnal tide constituent and by the phase shift between the semi-diurnal and the quarter-diurnal tide constituents. Furthermore, seasonal to annual residual migration does not account for effective dune displacements over shorter periods.

In mean tidal conditions, residual sediment pathways follow the asymmetry of tidal current phases on a long term basis, but can be temporarily reversed due to a change in the direction of storm and/or mean waves, without affecting long-term sediment transport (Grochowski et al., 1993; Van Dijk and Kleinhans, 2005). Buijsman and Ridderinkhof (2008b) observed that the largest seasonal variability in height and migration speed could be attributed to the tides or to a seasonal fluctuation in fall velocity, and concluded that the influence of storms on the dune variability in a tidal inlet is negligible. However, in the Strait of Dover, residual tidal movements are completely disturbed by storms, which can cause the 
inversion of movement (Le Bot and Trentesaux, 2004; Le Bot et al., 2000, 2006). Tobias (1989) also showed that dune and sandbank heights are subject to seasonal changes due to the increase in wave activity in winter, leading to the erosion of dune crests. Furthermore, in the eastern English Channel, observations of dune movements in the Bay of Somme reveal that migration speeds recorded on the decennial timescale are generally about 1.5 to 4 times higher than those obtained via the multi-decennial scale (Ferret et al., 2010). These results corroborate the idea that migration speeds seem to be correlated with the frequency of measurements for a given dune field (Garlan, 2004). This variable migration speed could imply that the tide is not the only hydrodynamic agent controlling dune movement, which may be also triggered by the inter-annual to decennial variability of storm activity in northern Europe (Ferret et al., 2010). It is thus essential to develop methods for obtaining accurate measurements during pluri-seasonal to annual recurrent surveys, in order to advance our understanding of dune dynamics in the short- to medium-term.

Spatial resolution and offset problems of depth sounding and single-beam echo soundings (SBES) have prevented precise multi-temporal measurements of dune migration rates for many years. This is particularly true for the dunes with the slowest migration rates (Knaapen, 2005; Kubicki, 2008). In addition, multi-beam echo soundings (MBES) were usually limited to 1D analysis (cross bathymetry section) for measurements of horizontal movement (Van Dijk and Kleinhans, 2005; Barnard et al., 2006). Recently, Duffy and Hughes-Clarke (2005) applied a spatial cross-correlation technique (Fig. 3) to determine the vectors of migrating bedforms in a more representative plane-view (2D). This technique was validated by Buijsman and Ridderinkhof (2008a), who measured a maximal migration rate of 90 m.yr ${ }^{-1}$ in tidal inlets (less than 25 m b.s.l). Van Dijk et al. (2008) also presented and compared two advanced methods of bathymetric signal separation (Kriging versus cross correlation analysis and 2D Fourier analysis) to separate and analyse dune dynamics in 2D. Following this approach, we have applied a new spatial cross-correlation technique to estimate 3D displacements in this paper, combined with a Digital Elevation Model (DEM) 
difference obtained from the data of three surveys, conducted over a time lapse of 19 and 11 months.

\subsection{Study area}

The study area (Fig. 1) is located about $10 \mathrm{~km}$ off the shore of western Brittany (France) and extends into the northern part of the Iroise Sea $\left(48^{\circ} 30^{\prime} \mathrm{N}, 05^{\circ} 00^{\prime} \mathrm{W}\right)$. The water depth ranges from 70 to $105 \mathrm{~m}$ L.A.T. This corresponds to the junction area between the English Channel and the North Atlantic Ocean, well known for having strong tidal currents and large swells. Indeed, the singular morpho-bathymetry of this segment of Brittany's continental shelf consists of a wide, northward-opened triangular bay, catalysing and amplifying marine hydrodynamics. It is bounded to the east by coastal reefs (plutonic rocks) and to the south and west by the Molene-Ushant Archipelago. This barrier is interrupted by two narrow, shallow channels, the Fromveur channel (60 m L.A.T) and the Four channel (13 m L.A.T.), whereby tidal current eddies, generated by the loading and unloading of the English Channel, become strong alternating unidirectional currents with surface velocities reaching up to $4 \mathrm{~m}^{-1} \mathrm{~s}^{-1}$ (Hinschberger, 1962). Moreover, Eulerian residual tidal currents, modelled by Guillou (2007) and the French Operational Coastal Oceanographic Centre, PREVIMER, reveal a clockwise current eddy occurring in the western part of the study area where a dominant north-eastward current extends along the coastal Four channel to the east (Fig. 1). The area is also exposed to the Atlantic storm waves coming from the NW. Their heights regularly exceed $4 \mathrm{~m}$, with wavelengths reaching over $200 \mathrm{~m}$, which impact on the seabed (Dehouck, 2006). The frequent rough seas could explain the limited number of studies devoted to the Banc du Four. The first survey was conducted by Hinschberger (1962) and allowed for the definition of the approximate morphology of the area and the highlighting of the massive volume of sand deposits. It also revealed that carbonate nature of the sediments. These are predominantly composed of organogenic debris with a mean grain size of about 0.8 to $0.9 \mathrm{~mm}$. Nevertheless, the location of sediment samples was quite imprecise 
and no relationship between the zonation of bathymetry and variations of granulometry was established. Except for this work, the Banc du Four has remained little studied until now.

\section{Data and methods}

\subsection{Data}

The results presented here are based on the data obtained during three MBES bathymetric surveys (Table 1). The first survey, EvalHydro2009, was carried out in February 2009 by the Service Hydrographique et Océanographique de la Marine (SHOM), using the oceanographic research vessel (R/V) "Pourquoi-Pas?". Soundings were gridded to a $5 \mathrm{~m}$ cell size, covering the entire sand body (Fig. 4). The second and third surveys, AlbertGeo2010 and AlbertGeo2011, were performed using R/V "Albert Lucas" in August-September 2010 and July 2011 by the "Institut Universitaire Européen de la Mer" (IUEM, UBO). For AlbertGeo2010, four Digital Terrain Models (DTM) of $2 \mathrm{~m}$ resolution were generated and named $A$ to $D$ to indicate different parts of the sand field: $A$ (sand spit), B (eastern part), C (western part) and D (eastern dune field) (Fig. 4). For AlbertGeo2011, two DTMs of $2 \mathrm{~m}$ resolution were generated, located on the sandbank and in the eastern dune field (Fig. 4). Additional historical bathymetric data provided by the SHOM were also used in order to follow the evolution of the Banc du Four on a larger temporal scale. The most complete data set was selected from two bathymetric surveys dating from 1926 and 1927, including 5545 points of depth sounding. The horizontal and vertical resolutions are $50 \mathrm{~m}$ and $1 \mathrm{~m}$, respectively.

\subsection{Methods/Analyses}

Marine dunes are described according to their morphological parameters (Fig. 2). Determining their contours was performed manually. To achieve an accurate digitisation, the sand bedform morphologies were analysed by generating and superimposing slope rasters and bathymetric DTMs, using ESRI ${ }^{\mathrm{TM}}$ ArcMap $9.3 \AA$ software. This allowed for tracing the 
crests and slopes of the structures. The morphological parameters were measured either manually or automatically and were compared to the results of previous dune studies, such as those of Knaapen (2005). For each dune, the wavelength $\lambda$, the lee side length $L_{s}$ and the height $\mathrm{h}$ were manually derived from at least three cross-sectional profiles perpendicular to the wave's crest. Reading of the values was carried out with $5 \%$ error. The lee side length is the horizontal distance between the crest and the nearest trough. The dune height is defined as the vertical distance between the crest and the base. The crest depth $D$ and dip direction of a lee side $\alpha$ are defined automatically by zonal statistics (mean, minimum, maximum and standard deviation) on bathymetric and slope rasters, respectively. The asymmetry $A$ is defined as $\left(\lambda-2 L_{s}\right) / \lambda$ (Knaapen, 2005). The effect of the regional seafloor slope can alter this last measurement if greater than $10^{\circ}$ but it could be considered to be negligible in our study (Xu et al., 2008).

Temporal depth comparison was performed by subtracting successive EvalHydro2009 grids from the AlbertGo2010 grids and the AlbertGeo2011 grids, using the same resolution (5 $\mathrm{m})$. These two latter DTMs were resampled to a $5 \mathrm{~m}$ grid, in order to achieve consistency with the EvalHydro2009 DTM. The vertical differential was used to identify accretion and erosion areas and to quantify these processes. Dunes do not necessarily move in a direction perpendicular to their crests. Consequently, horizontal movements cannot always be measured by tracking dunes along cross-sections. To circumvent these difficulties, the dune migrations were measured by using a spatial cross-correlation technique. This method was previously used by Delacourt et al. (2004) to measure 2D displacements of a landslide, as well as by Duffy and Hughes-Clarke (2005), who applied it to sand bedforms in shallow waters. According to this technique, the maximum correlation of shapes between two grids is obtained for two different times, $\mathrm{t} 1$ and $\mathrm{t} 2$ (Fig. 3). The migration vector is then calculated by means of the weighted centroid method. To this end, the grids were sun-illuminated from the NE direction, which allowed for the highlighting of the slopes of the sand structures. Hillshaded grids were calculated from the EvalHydro2009 DTM, the AlbertGeo2010 DTM and the AlbertGeo2011 DTM. The spatial correlation analysis was performed by a code written in 
ITT TM IDL $®$ programming language. The output of the code consists of three arrays: projections of the migration vectors on the vertical (directed to the north) and horizontal (directed to the east) axes, as well as Signal-to-Noise Ratio (SNR), allowing to for the quantification of the quality of the result.

The temporal comparison between old and recent bathymetries is more difficult, due to the incertitude of the depth sounding positioning and irregular sampling. The distance between each depth sounding does not allow for the recognition of objects the size of dunes and thus cannot follow their evolution over a long period of time. However, it is possible to partially reconstruct the general morphology of the sedimentary package of the Banc du Four. To do this, two bathymetry grids were performed by means of the Kriging interpolation (Fig. 5). The first one was calculated from the 1926-1927 data set. The second one was calculated using the same 1926-1927 sampling sounding, with corresponding 2009 depth values. This method allows for the comparison of two bathymetry DTMs with the same sampling errors and interpolation errors.

\section{Result}

\subsection{Morphology}

The morphological analysis of the dunes was performed using the bathymetric data collected during the 2009 survey, since its coverage is much larger than that of the 2010 and 2011 surveys (Fig. 4). The dimensions of the smallest detectable features are approximately twice the DTM resolution and are equal to $10 \mathrm{~m}$ and $0.2 \mathrm{~m}$ in horizontal and vertical directions, respectively.

\subsubsection{Dune zonation}

The surveyed area covers $18 \times 14 \mathrm{~km}^{2}$ and the water depth ranges from 35 to $105 \mathrm{~m}$. It is bounded to the east and south by rocky reefs and ridges that outcrop from the seabed. Farther offshore, the rocks are overlaid by a Tertiary series (Lapierre and Bouysse, 1975), draped by a spectacular series of bedforms extending between 70 to $105 \mathrm{~m}$ L.A.T. The Banc 
$d u$ Four is characterised by a principal feature, referenced as the main system, and is flanked by two dune fields (western and eastern fields) that define its $V$ shape (Fig. 6).

The main system extends to the south. The bathymetry varies between 35 and $90 \mathrm{~m}$ L.A.T. Its morphology is characterised by a large sandbank and a giant dune that overlaps with a flat, rocky reef located between 50 and 70 m L.A.T. The sandbank covers an area of $4 \times 2 \mathrm{~km}^{2}$, with a maximum thickness of $45 \mathrm{~m}$ measured by bathymetric sections ranging from 35 to $80 \mathrm{~m}$. The crest is flattened and trends in the E-W direction. The bank is nearly symmetrical $\left(4^{\circ}\right.$ and $3^{\circ}$ for lee and stoss angles, respectively), with a lee slope oriented towards the SW. Small dunes ( $\lambda$ about $2 \mathrm{~m}$ ) superimpose the structure. To the east, a submarine, southward-pointing sand spit extends for about $1.2 \mathrm{~km}$ and is $0.2 \mathrm{~km}$ wide with water depths ranging between $70 \mathrm{~m}$ and $80 \mathrm{~m}$ L.A.T. It is flanked to the west by barchanoidshaped dunes of $2 \mathrm{~m}$ high and $80 \mathrm{~m}$ long. To the SW, a giant dune $(\lambda=1050 \mathrm{~m}, \mathrm{~h}=32 \mathrm{~m}$, width=2000 m) is based at $80 \mathrm{~m}$ L.A.T. The straight crest is oriented in the NW-SE direction and the bedform presents asymmetrical slopes $\left(5^{\circ}\right.$ and $\left.15^{\circ}\right)$ with lee sides oriented towards the SW. Only the stoss side is superimposed by small dunes (Fig. 4).

The western field is a dune field that covers an area of approximately $10 \times 10 \mathrm{~km}^{2}$ and which tapers to the NE. Dune sizes also decrease in this direction (between 0.06 and $30 \mathrm{~m}$ high and with a wavelength between 10 and $600 \mathrm{~m}$ ), while the water depth increases from 50 to $105 \mathrm{~m}$ L.A.T. The western field exhibits various morphologies of dunes (Fig. 7), except for those with barchanoid shapes. They are generally asymmetric, with sinuous crests and an orientation of polarities that rotate progressively north-westward in a clockwise direction, from SW to NE. However, a few symmetrical and trochoidal-type dunes can also be observed in the center of the system (Fig. 4).

The eastern field consists of a wide dune field outlining a triangular shape, pointing to the NE. The heights of the dunes range between 0.2 and $20 \mathrm{~m}$, while their wavelengths vary between $25 \mathrm{~m}$ and $500 \mathrm{~m}$ (Fig. 6). As observed in the western field, dune sizes decrease when the water depth increases north-eastward from the main system. Dune crests are usually more sinuous, or even barchanoid, with 3D shapes in the eastern part and are mostly 
straight towards the west; however, they are broadly oriented $\mathrm{N} 100^{\circ}$. Dunes are mainly asymmetric with reverse orientations of polarities along the eastern and western parts of the field. In the eastern part, the lee sides are oriented towards the SW and are oriented inversely in the western part. The separation is manifested by a well-marked shear zone, where several bifurcation points are observed. The zoning is marked by a greater crest sinuosity and the smaller size of the dunes in the eastern part. As observed in the giant dune of the main system, smaller dunes are superimposed over the stoss sides (Fig. 8).

\subsubsection{Dune morphology}

500 dunes have been identified and measured on the DTM (Fig. 6). They exhibit a wide range of morphologies that occur in distinct assemblages. In over $90 \%$ of cases, the crests are easy to identify, even if most of them (more than $75 \%$ ) are quite smooth. Nevertheless, a few of them exhibit sharp, cat-back morphologies (McCave, 1971) as the giant dunes of the main system (Fig. 7I). Crest geometries are largely straight to slightly sinuous (2D) and few 3D bedforms (Fig. 7) are observed along the eastern part of the eastern field (less than $20 \%$ ). The wavelength of the bedforms varies according to a wide range, from $10 \mathrm{~m}$ (the smallest object size detectable in the horizontal direction) up to $1050 \mathrm{~m}$. The mean $\lambda$ is 125 $\mathrm{m}$, with a high value of Standard Deviation (STD) equal to $101 \mathrm{~m}$. The frequency distribution shows more than 250 dunes have a wavelength smaller than $100 \mathrm{~m}$. Fewer than seven dunes have a wavelength of over $500 \mathrm{~m}$.

The height measurement is also limited by the vertical precision of $0.2 \mathrm{~m}$. The maximum measured $\mathrm{h}$ is $32 \mathrm{~m}$ and corresponds to the giant dune mentioned above (Fig. 6). The mean value of $\mathrm{h}$ is $4 \mathrm{~m}$, with a STD=4 $\mathrm{m}$. The frequency distribution shows the same trend as the one observed for the wavelengths. The mode shows more than 250 dunes less than $3 \mathrm{~m}$ high. Only eight dunes are higher than $15 \mathrm{~m}$ (Fig. 6).

The asymmetry parameter $A$ varies from 0 (symmetrical dunes) to 0.51 . Its mean value is 0.3 , with a high STD value (0.2) and two modes ( 0.2 and 0.4$)$. More than $50 \%$ of the dunes 
have an asymmetry parameter lower than 0.3 . The frequency distribution remains globally stable for the index between 0 and 0.5 and decreases beyond this value.

The crest depth $D$ varies from 54 to $103 \mathrm{~m}$ L.A.T. It is characterised by a mean value of $85 \mathrm{~m}$ and a low standard deviation (STD) of $11 \mathrm{~m}$. The mode is centred on the mean value, with 194 dunes having a crest depth between 80 and $90 \mathrm{~m}$ L.A.T.

\subsubsection{Relation between morphological parameters}

Similar to Flemming (2000), we estimated the relationship between the $h$ and the $\lambda$ of the dunes. The dependence $h=0.0139 \lambda^{1.164}$ was obtained with a variance coefficient of $r^{2}=0.75$ (Fig. 9). From Figure 9, it can be seen that the majority of the points are homogeneously distributed around the regression. For $\lambda$ greater than $100 \mathrm{~m}$, heights are generally higher than the global mean. Figure 9 also shows that the dependence between $\mathrm{h}$ and $\lambda$ for dunes of the Banc du Four has a steeper positive slope when compared to those reported in other publications (Dalrymple et al., 1978; Flemming, 2000; Francken et al., 2004; Van Landeghem et al., 2009a), while some values exceed the upper threshold calculated by Flemming (2000).

At the same time, no clear relationship between $A, \lambda$ and $h$ can be deduced; in both cases, calculated correlations have variance coefficients of $r^{2}<0.1$. In addition, no clear link was observed between asymmetry and crest depth $D\left(r^{2}<0.1\right)$. Nevertheless, there seems to be a relationship between size parameters and crest depths (Fig. 10). The general trend shows that $h$ (and similarly $\lambda$ ) decreases gradually with $D$, even if a large range is observed in terms of size (height and wavelength) or depth. The largest calculated variance coefficient (0.28) was found for the linear regression equation $h=9561.10^{3} D^{-3.3823}$. The observed inverse relationship between $\mathrm{h}$ and $\mathrm{D}$ is different from that found by other authors (Yalin, 1964; Allen, 1968; Van Rijn, 1984; Van Landeghem et al., 2009a). Moreover, for some dunes, the ratio of $h$ and $D$ exceeds $\lambda$, the upper limit of $h_{\max }=0.25 P$ calculated by Francken et al. (2004). 


\subsection{Migration and sedimentary budget}

To confirm the validity of our dynamic assessment approach, a comparison of the three bathymetric data sets was performed on stationary arrays (bedrocks, surrounding seafloor). The comparison showed that the variation between the three bathymetric profiles was less than was the vertical system precision limit $(<0.1 \mathrm{~m})$. A similar test on the measurements of the horizontal migrations detected migration rates of less than $2 \mathrm{~m}$, well below the horizontal resolution system $(<5 \mathrm{~m}$ ) (Fig. 8). The migrations were controlled and validated by visual methods (Fig. 11).

\subsubsection{Erosional and accretionary budgets}

For long-term monitoring, the comparison between DTM 1926-1927 and DTM 2009 revealed a stable surface of the Banc du Four and the outer limits of the Banc du Four remained unchanged during the 82-year period between the two surveys (Fig. 5). The imprecision of the ancient data set prevents the assessment of vertical movement. Nevertheless, the comparison of the respective location of the $50 \mathrm{~m}$ isobath shows that the southern flank of the sandbank was eroded, whereas the eastern part is accreted. The western dune field also appears to be eroded. The short-term vertical change is described by the bathymetric differential images, showing the erosional and accretionary zones between February 2009, August-September 2010 and July 2011. For the years 2009-2010, the values range from $-4.0 \mathrm{~m}$ to $+10.1 \mathrm{~m}$ for the differential bathymetry. The lower dynamic area is observed through the swath survey zone $A$, with values ranging from $-3.5 \mathrm{~m}$ to $2.2 \mathrm{~m}$, and a standard deviation of 0.1 . The most dynamic is zone $D$, where the values range from $-4 \mathrm{~m}$ to $10.1 \mathrm{~m}$, with a standard deviation of 1.1 (Fig. 8). For the years 2010-2011, the differential bathymetry values range from $-12.4 \mathrm{~m}$ to $12.9 \mathrm{~m}$, with the most dynamic still corresponding to the northern area (eastern field). The average value of all the vertical movements obtained from the comparison of the different DTM images is $0 \mathrm{~m}+/-0.2 \mathrm{~m}$. This suggests an absence of change in the sediment volume on a large scale and an equilibrate balance between input/output sediment supplies across the entire area under study. 
A more detailed examination of the spatial distribution of the vertical change reveals that accretions of the zones $B$ and $C$ are localised on the crests of dunes superimposed on the sandbank, while the erosional zones are localised on the lee slope. However, both of these zones have a similar bathymetry between 2010 and 2011. Zone A does not show a characteristic location of erosion and accretion trends. In contrast, zone D shows a different evolution, with accretion restricted to the lee sides and, inversely, erosion of the stoss sides. In this case, the displacements are horizontal rather than vertical (Fig. 11). However, when these horizontal displacements are ignored in bathymetric profiles, these show an accretion of crests and an erosion of the sides of the dunes. Overall, the vertical dynamic can be summarised by the remobilisation of sandy material from the slopes (erosional), which was deposited on the crests between February 2009 and August-September 2010 / July 2011. This dynamic does not imply change in the sediment budget as mentioned above. This result is also in agreement with the null sediment balance.

\subsubsection{Horizontal movements}

As mentioned above, the horizontal movement is detected only in the eastern field, where the bathymetric data set allowed for the measurement of migration. The spatial crosscorrelation method was used to determine the horizontal vector migration of the dunes. Parameters corresponded to a search window size of 32 pixels and a size fit matrix of 8 pixels, with $95 \%$ of the SNR values higher than 0.9 . The values chosen are those with an SNR above 0.99 and a magnitude vector greater than or equal to $5 \mathrm{~m}$. Migration is expressed as speed in meters per year. The results give more than 4000 migration values for 37 dunes observed over periods of 19 and 11 months. In order to streamline the results and to characterise the individual dune movements, average vectors were calculated for each dune. Velocities varied between 3 m.yr ${ }^{-1}$ and 20 m. $\mathrm{yr}^{-1}$ for 2009-2010 and 2010-2011. The mean value is equal to $8 \mathrm{~m} . \mathrm{yr}^{-1}(2009-2010)$ and $10 \mathrm{~m} \cdot \mathrm{yr}^{-1}$, with some important differences regarding these values (STD=5 m. $\mathrm{rr}^{-1}$ for three consecutive years) and an important range of directions of horizontal movements. The frequency distribution of the average directions 
presents values more concentrated around the two modes ( $\mathrm{N} 045^{\circ}$ and $\left.\mathrm{N} 225^{\circ}\right)$. These peaks represent more than $75 \%$ of the value. More than $75 \%$ of the dunes have a difference between the migration direction and the crest direction lower than $30^{\circ}$ (values ranging from 0 to $179^{\circ}$ ) and, consequently, the horizontal migrations are mostly perpendicular or slightly oblique to the crests (Fig. 12). The differences in velocity between 2009-2010 and 2010-2011 range between $-9 \mathrm{~m} \cdot \mathrm{yr}^{-1}$ and $+12 \mathrm{~m} \cdot \mathrm{yr}^{-1}$, but with an average of less than $-1 \mathrm{~m} \cdot \mathrm{yr}^{-1}$.

\subsubsection{Migration fields}

Migration fields are easily distinguished by the directions and lengths of the displacement vectors. As seen previously in the morphological analysis of the eastern field, the area can be subdivided in three parts with respect to the dunes' dynamics, namely eastern, western and central shear parts.

In the eastern part, the migration rate estimated for $2009-2010$ ranges from $7 \mathrm{~m}_{\mathrm{yr}} \mathrm{r}^{-1}$ to $20 \mathrm{~m} . \mathrm{yr}^{-1}$, with a mean value of $12 \mathrm{~m} . \mathrm{yr}^{-1} 1$ and an STD=4.4 m.yr ${ }^{-1}$. For 2010-2011, values range from $3 \mathrm{~m} \cdot \mathrm{yr}^{-1}$ to $20 \mathrm{~m} \cdot \mathrm{yr}^{-1}$, with a mean value of $11 \mathrm{~m} \cdot \mathrm{yr}^{-1}$ and an STD=5.1 m. $\mathrm{yr}^{-1}$. For the entire period, the average dune direction movement was concentrated around $\mathrm{N} 045^{\circ}$, with velocities increasing towards the north-east.

In the western part, the calculated straight crest migration rates are slower, ranging from $3 \mathrm{~m} \cdot \mathrm{yr}^{-1}$ to $10 \mathrm{~m} \cdot \mathrm{yr}^{-1}$, with a mean value of $6 \mathrm{~m} \cdot \mathrm{yr}^{-1}$ and an STD=1.9 m. $\mathrm{rr}^{-1}$ for 20092010. For 2010-2011, the values range from $3 \mathrm{~m} \cdot \mathrm{yr}^{-1}$ to $16 \mathrm{~m} \cdot \mathrm{yr}^{-1}$, with a mean value of 7 $\mathrm{m} \cdot \mathrm{yr}^{-1}$ and an STD=2.3 m.yr ${ }^{-1}$. Dunes migrate in one preferred direction, a mode equal to $\mathrm{N} 225^{\circ}$, with very low variability and with rates increasing towards the outer north-eastern summit in a constant direction for the entire period.

These two parts are separated by a central section with chaotic crests of shearing, where average directions range from $\mathrm{N} 005^{\circ}$ to $\mathrm{N} 197^{\circ}$ with no preferred direction. For 20092010 , the average migration speeds calculated for the nine listed dunes across this shear zone present velocity rates ranging from $3 \mathrm{~m} \cdot \mathrm{yr}^{-1}$ to $15 \mathrm{~m} \cdot \mathrm{yr}^{-1}$, with a mean equal to $7 \mathrm{~m} \cdot \mathrm{yr}^{-1}$ 
and an STD=4.4 m.yr ${ }^{-1}$. During 2010-2011, the values ranged from $3 \mathrm{~m} \cdot \mathrm{yr}^{-1}$ to $19 \mathrm{~m} \cdot \mathrm{yr}^{-1}$, with a mean value of $8 \mathrm{~m} \cdot \mathrm{yr}^{-1}$ and an STD $=5.9 \mathrm{~m} \cdot \mathrm{yr}^{-1}$.

\subsubsection{Migration rates compared to size parameters}

The evolution between the size parameters $(\lambda$ and $h)$ and migration rates were also examined for the two observation periods (September 2010 in relation to February 2009, and July 2011 in relation to September 2010). Figure 13 (A and B) shows the height (h) as a function of the migration rate throughout the eastern field, where displacement speeds are significant. The correlation depends on the geographic sections of the bedform field. In the eastern part, the range of velocities is higher than it is in the western part and the velocity tends to be slower with the increase in size, even if dunes migrate within an important range of speeds for small dimensions. Despite the significant difference between the two periods, this trend was observed from 2009 to 2011. In contrast, the migration rates tend to be more stable and lower than 8-10 m. $\mathrm{yr}^{-1}$ in the western part, where the dunes are more linear and do not fluctuate with an $\mathrm{h}$ parameter confined between 5 and $12 \mathrm{~m}$ (excluding the shear zone).

The relationship between the migration rates and the asymmetry is considered to be a solid indication of the residual flow direction, while associated net bedload transport was also tested (Fig. 14, A and B). As regards dimension parameters, the evolution depends on the area under study. In the western part, the degree of dune asymmetry increases slightly with the migration rate. This trend is better observed for the 2010-2011 period. By contrast, it seems that no clear trend occurred in the eastern part. The great variability of asymmetry is only regularly observed where the flexing of the upper part of the crest of the dunes is important and contrasts with the western part of the field, which is characterised by elongated and linear crests. 


\section{Discussion}

\subsection{Bedform classification}

The classification of the sandbank itself is difficult to establish because of its atypical shape (Dyer and Huntley, 1999; Kenyon and Cooper, 2004). Its rounded and smooth crest is hardly perceptible and its roughly W-E extension is neither parallel nor perpendicular to the residual current, which is oriented towards the NE (Fig. 1). This morphology means that it cannot be considered to be representative of an open shelf ridge marked by straight to slightly sinuous crests with orientations at a small oblique (about 7 to $15^{\circ}$ ) to the peak tidal flow direction. Otherwise, banner sandbanks are commonly attributed to the presence of a tidal, residual current eddy, as observed here. The Banc du Four could also be considered to be representative of this type of bank. Indeed, eddies are generated by a tidal flow that is disrupted by a coastal promontory or island like the Ushant-Molene archipelago in the studied area (Neill and Scourse, 2009). Nevertheless, the banner banks exhibit typically associated parallel sand ridges not observed in the surveyed area.

Thus, the non-consistent morphology of the sandbank could find a partial explanation in the interference resulting from the current eddy to the west and the coastal current to the east. This renders hydrodynamic modelling difficult (Sentchev et al., 2011) and adds to the lack of in-situ measurements, preventing the precise determination of the hydrodynamic context and the morphologies of induced bedforms. Nevertheless, the significant obliqueness of the crest bank, relative to the orientations of the different residual currents, leads to the consideration of other factors in the bank build-up. In this regard, it is highly probable that initiation of the growth and development of the bank started at a time of lower sea levels during the last post-glacial transgression, when the hydrodynamics were very different from present day conditions. We suggest that progressive flooding of bathymetric thresholds corresponding to channels separating islands around the Banc du Four (Fromveur channel $60 \mathrm{~m}$ L.A.T.) to the west and the Four channel (13 m L.A.T.) to the south (Fig. 1) have generated very different tidal currents during the post-glacial transgression. These different 
hydrodynamic conditions are probably the reason for the main E-W orientation of the bank. This change of orientation, related to sea level rise, was also mentioned with regard to the North Sea (Hoffman, 2005). Thus, the Banc du Four is a partially relict feature created during the last post-glacial rise, even if the time series of bathymetric data shows that its surface is still active and exhibits attached dune fields in accordance with present hydrodynamics.

Moreover, the numerous dunes offer a large spectrum of shapes and sizes observed throughout the small and deep area under study $\left(18 \times 14 \mathrm{~km}^{2}\right)$. This variability is quite uncommon and most of the local studies devoted to bedforms occurring on tidal continental shelves report limited types of dune shapes. This is partially due to previous, low-resolution data that could not take the smallest bedforms into account (Van Dijk et al., 2008). As mentioned with regard to the Irish Sea, it also seems that where dunes occur abundantly, the variability in dune geometry becomes larger over short distances (Van Landeghem et al., 2012). Here, the 500 analysed dunes exhibit a great diversity in size, ranging from accurately scaled bathymetric grids (10 m wavelength and $0.2 \mathrm{~m}$ height) to giants with the largest scale known (1050 m wavelength and $32 \mathrm{~m}$ height). Considering the Eulerian residual tidal currents (Fig. 1), this giant dune is located downstream from the bank and has a stoss side facing NNE, fed by sediments from the bank. Its size is very similar to dunes recently observed in the Irish Sea, where the tidal regime and depths are quite similar to the Brittany continental shelf (Van Landeghem et al., 2009a, 2009b). Therefore, such giant dunes would not be uncommon on deep macro-tidal continental shelves where sediment supplies are abundant, as observed in the Banc du Four field and the Irish Sea.

\subsection{Equilibrium conditions}

The analysis of the entire dune area allows for the establishment of good heightspacing $(\lambda, h)$ and power law correlation, despite the wide range of morphologies. Nevertheless, the results do not match the global mean statistical regression that was compiled by Flemming $(1988,2000)$ from flume studies and various sedimentary environments. The steeper positive slope of the equation and the outstanding values of the 
height limit suggest complex physical mechanisms and hydrodynamic regimes in the dune build-up. These results are also different from the correlation established from analyses of the Irish Sea flow-transverse dunes, which show similarities to the regression compiled by Flemming (1988) and Van Landeghem et al. (2009a). The bathymetry and depths of the Irish Sea shelf are quite close to conditions prevailing on the Brittany continental shelf, but the difference in results suggests that the hydrological setting and the depth are not the only significant factors in dune growth.

Other parameters, such as bed conditions associated with the quantity, nature and mobility of sediments must also be taken into account (Barnard et al., 2012). At most sites in the Irish Sea, coarser grained sediments (median grain diameter $d_{50}$ about $1 \mathrm{~mm}$ ) tend to form higher sediment waves in response to local hydrodynamics. As mentioned above, the grain sizes of the sediments shaping the Banc du Four are about the same (mean grain size about 0.8 to $0.9 \mathrm{~mm}$ ), but their lithology is different. They correspond to glacial and postglacial deposits in the Irish Sea, while biogenic coarse sands prevail throughout the Banc du Four. The flat-shaped bioclastic particles reveal a good resistance to flow friction when imbricated in the sediment and the biogenic sand shows a higher capacity for bed armouring than can be seen in silicoclastic sediments (Weill et al., 2010). Furthermore, the maximum growth rates of the sandwaves are estimated for the larger values of the resistance to flow friction parameters, as well as to maximum height increases (Németh et al., 2007). In consequence, the specificity of the height-spacing power law correlation obtained for the Banc du Four field could be inferred from the main bioclastic nature of the sand.

Moreover, results show that the evolution of height $h$ varies weakly with the water depth $\mathrm{D}$ and tends to show a negative correlation, unlike the predictive equations compiled by other authors (Van Landeghem et al., 2009a). The $\mathrm{h}$ values also exceed the upper limit of crest height relative to depth established by Francken et al. (2004) and again suggest that the Banc du Four field is characterised by outstandingly high, elevated dunes. In any event, the water depth cannot be considered to be a major controlling factor. Recent works devoted to the process of the formation of tidal dunes have shown that predictions of the wavelengths 
of tidal dunes are strongly dependant on the mean water depth (Besio et al., 2006; Blondeaux and Vittori, 2011) and tend to be correlated (Van Santen et al., 2011). Nevertheless, these approaches provide accurate results for shallow waters, as well as when the ratio between the local water depth and the wavelength of the bedforms is very small $(<0.05)$. Neither of these conditions were observed here $(D / \lambda>0.33)$. In contrast, our results showed an absence of correlation between dune size and water depth, confirming the results of other recent studies in shelf seas (Aliotta and Perillo, 1987; Landeghem et al., 2009a; Flemming and Bartholomä, 2012). Finally, no relationships were observed between asymmetry and other morphological parameters; the maximum A values (0.51) remained below those of observations in the Irish Sea $\left(A_{\max }>0.7\right)$ (Van Landeghem, 2012).

\subsection{Morphology changes and hydro-sedimentary processes}

Analysis of bathymetric data dating back to 1926-1927 shows that the bank has been stable over the last 80 years, even though a slight shift in sediment was observed from the western part of the bank to the eastern part (Fig. 5). The maintenance of the sandbank at the same place has thus been observed over historical time, in spite of the active migration attested to by the spatial distribution of dunes over the entire zone and measured throughout the eastern dune field. Moreover, the differential rasters performed by subtracting the three DTMs show significant local vertical variation of bathymetry between February 2009, September 2010 and July 2011, revealing that the total sediment balance is null for all the dune fields that were analysed. This result confirms the stability of the sand reservoir over historical time with the absence or very limited exportation or importation of shelf sediments from other parts of western Brittany. As already observed, in many cases the movement of sand over and around the bank leads to a near equilibrium configuration in order for the sandbank to be stable and self-sustaining although the sand is still mobile (McCave and Langhorne, 1982; Dyer and Huntley, 1999).

The total mean variation computed from the annual surveys also revealed that the crests are accreted, whereas the slopes are eroded (Fig 11). This observation is compatible 
with theoretical linear stability analyses (Hulscher, 1996); they show that sandwaves form due to the rectification of oscillatory tidal currents, generate residual circulation cells causing flow convergence over the crests and favour the growth of the bedform. Nevertheless, the main morphological changes were observed winter (survey 2009) and summer (surveys 2010 and 2011), which suggests a seasonal variability in the dunes' heights. As mentioned above, this morphological difference can be explained by the action of strong winter waves rounding the sand bedforms (Tobias, 1989; Van Dijk and Kleinhans, 2005), whereas the building of sharp-crested dunes are assumed to be the result of tidal current bedforms. Moreover, asymmetrical tidal residual circulation and the presence of subordinate currents over crests can explain the locally observed, cat-back morphologies (McCave, 1971). This assumption is confirmed by the observation data from the French Operational Coastal Oceanographic Centre Previmer, which reported significant wave heights across the Iroise Sea, reaching about $6 \mathrm{~m}$ during March 2009 and attaining more than $7 \mathrm{~m}$ during November 2010. These storm waves have wavelengths of over $200 \mathrm{~m}$, with orbital velocities at the seabed reaching $0.8 \mathrm{~m} \cdot \mathrm{s}^{-1}$, susceptible to the movement of millimetric sand grains (Brown et al., 1989).

Moreover, the horizontal short-term changes deduced from the three surveys revealed that only the eastern field shows significant horizontal variations. This result is quite different from the first studies of Hinschberger (1970), who deduced a general northward migration of the Banc du Four from the offset of two successive $50 \mathrm{~m}$ isobath curves drawn from historical data (1897 and 1962). Nevertheless, the localisation of the data suffered from a lack of accuracy and the validity of the measurements was not checked by controlling for the absence of movement on selected rocky outcrops at the seabed. As mentioned above, the lack of accuracy does not allow for the comparison of the 1926-1927 bathymetric data with the recent surveys in order to deduce the horizontal migration rate for individual dunes. The spatial cross-correlation method used in this study reveals migration rates ranging from 3 to 20 m.yr ${ }^{-1}$ and shows that they are increasing in a north-eastward direction. Despite the fact that the 2009 and 2010 surveys have a greater time span (19 months) than the 2010-2011 
surveys (10 months), the horizontal displacements are proportionally more pronounced for the first period (Fig. 11) and reveal that migration rates are not as regular during short periods. Reasons for such differences remain unconfirmed, but could be linked to more frequent storms during 2009 and 2010. As observed by Giardino et al. (2010), the influence of wave activity leads to an increase in residual transport, which is more pronounced at bedform crests. In addition, values are of the same order of magnitude as observed in the North Sea and the Irish Sea (Le Bot, 2001; Van Dijk and Kleinhans, 2005; Ferret et al., 2010) but the previously published data were primarily collected in shallow waters of less than $50 \mathrm{~m}$ deep. Thus, the new data provide a constrained quantification of very large to giant dunes that migrate on the deep continental shelf (>70 m L.A.T.) and attest to their still present morphodynamic equilibrium. The results are in agreement with bottom residual velocities, calculated by a hydrodynamic model (Guillou, 2007). Velocities obtained for the eastern field are higher than $0.5 \mathrm{~m} . \mathrm{s}^{-1}$ at spring tide and are sufficient to establish sedimentary transport (mean grain size about $0.9 \mathrm{~mm}$ ), while lower velocities corresponding to the western field could explain the low migration rates.

The spatial variation of migration directions measured throughout the eastern field reveals two opposing dynamic sections. In the eastern part, dune migrations are fast (mean equal to $12 \mathrm{~m}_{\mathrm{yr}} \mathrm{yr}^{-1}$ ) and towards the NE, while conversely, the western part is characterised by lower velocities (mean equal to $6 \mathrm{~m}_{\mathrm{yr}} \mathrm{yr}^{-1}$ ) and an opposing migration direction (SW). The difference in the migration rate could be simply induced by the dominant, northward flood tide residual current throughout the area and could be enhanced by the down-slope migration of the large underlying morphology to the east and the down-slope towards the west. However, another cause needs to be invoked to explain the reverse direction of sediment transport on both sides of the dune field. This gives rise to an anti-clockwise sedimentary displacement within the eastern field.

In contrast, the NE-SW orientation of the entire eastern field itself shows a slightly clockwise, angular shift from the N-S trending general residual tidal current occurring throughout the area (Guillou, 2007). This spatial organisation, including a residual vorticity 
within the bedform field, was previously described in tidal dominated environments for shelf ridges in which an asymmetry in the current strength on either side of the bank, maximum currents being in the ebb direction on one side and in the flood direction on the other, caused sediment accumulation (Caston and Stride, 1970; Huthnance, 1973; McCave and Langhorne, 1982). It is assumed to be the combined effects of Coriolis and friction forces above the seabed that generate the horizontal deflection of the oscillatory flow over tidal ridges (Huthnance, 1973; Pattiaratchi and Collins, 1987; Trentesaux et al., 1999; Dyer and Huntley, 1999). Thus, the sedimentary dynamics observed in the eastern field could be considered to be equivalent to the response of an open shelf sandridge to tidal dynamics. $A$ such migration showing opposite directions was also observed for banner bank in Bristol Channel (Schmitt et al., 2008). As mentioned above the absence of successive parallel sandridges in the eastern field leads to consider it as not representative of this type of bank. Another point concerns the compatibility of the long-term stability of the sandbank in regard to the active migration observed along the eastern field, as observed previously off the Norfolk coast in the North Sea (McCave and Langhorne, 1982). It suggests that the route by which sand travels around the northern end of the eastern field forms a roughly closed circulation.

\subsection{Geometry as predictive migration}

Results show that dunes' morphological directions deducted from the crest horizontal translation are coherent with migration directions obtained by spatial cross-correlation (Fig. 12). More than $75 \%$ of dunes have a difference between the migration direction and the crest direction, which is lower than $30^{\circ}$ from normal. The largest values correspond to the shear zone located at the centre of residual vorticity. This part encloses several sinuous crests and bifurcation points where dunes behave more dynamically. This was previously pointed out by Van Dijk et al. (2008) from case studies of the North Sea. Consequently, even if the horizontal migrations are mostly perpendicular or slightly oblique to the crests, and if the crest's horizontal correlation method gives acceptable results for first order analysis, it is thus 
important to consider the lateral behaviour of crests and migrations along crests, as considered in this study.

Concerning the evolution between the size parameters $(\lambda$ and $h)$, the results obtained for the Banc du Four show that velocity tends to be slower with the increase of size, even if dunes migrate within an important range of speed for small dimensions. These results are in agreement with previous observations in the North Sea (Ernstsen et al., 2006). In any event, the variance coefficients calculated for the dunes of the Banc du Four are less than 0.1 , and thus no power-law relationship equation between dune migration rates and size can be deduced, as pointed out by Van Landeghem et al. (2012). Furthermore, other studies have shown an inverse correlation (Garlan, 2004) The absence of a statistically predictive method for determining the relationship between sizes and migration rates also suggests that other parameters, such as sediment supply and grain size, need to be taken into account. The recent development of numerical models, including the variability of grain size, argues for this approach (Van Oyen and Blondeaux, 2009).

The relationship between the migration rates and the asymmetry shows that the degree of dune asymmetry increases slightly along with the migration rate in the western part of the eastern field. This observation, which supports the findings reported in the literature, follows the idea that migration velocity and asymmetry rates both depend on the residual current amplitude. Based on this relationship, Knaapen (2005) and Xu et al. (2008) used the degree of asymmetry to estimate migration rates through geometry-based predictors and a comparable approach seems acceptable in this study. However, no such relationship was observed in the eastern part and this result is also in agreement with certain previous observations reported by Van Landeghem (2012) regarding the Irish Sea, where it was found that migration rates are not significantly influenced by the asymmetry of the adjacent dunes. Here, the absence of current measurements at the seabed prevents a definitive declaration regarding the influence of the strength of residual currents on asymmetry. In addition, the percentage of dunes in the Irish Sea that migrate in the opposite direction as inferred from 
their asymmetry remains at $18 \%$. The results from the eastern field of the Banc du Four do not show such reversed-asymmetry migration.

In a more general view, the contrasting geometry of dunes located on both sides of the eastern field of the Banc du Four seems to be controlled by a threshold of about 8-10 m. $\mathrm{y}^{-1}$, above which dune morphologies change with the increasing flexing of crests. When they acquire a morphology that changes from $2 \mathrm{D}$ to $3 \mathrm{D}$ or that is transitional, as observed in the western and eastern sections, they no longer follow a correlation between migration rates and asymmetry and they tend to be smaller for higher velocities. This could be due to constant rearrangement of crest lines that characterised the evolution of 3D dunes (Venditti et al., 2005).

\section{Conclusion}

The Banc du Four bedform field, located off the shore of Brittany, offers the opportunity to study the spatio-temporal variability of very large dunes in a deep, tide-dominated environment. The realisation of three recent 29-month spaced swath bathymetric surveys of the area, complemented by an historical data set has allowed the accurate quantification of dune migration rates and the discussion of the validity of the bedform geometry predictive equations defined in shallow waters. The sandbank itself is assumed to be a partially relict feature, created during the last post-glacial sea-level rise and its surface is still active, exhibiting attached dune fields in accordance with present hydrodynamics.

Concerning the morphology and equilibrium conditions, this $112 \mathrm{~km}^{2}$ bedform field is composed of more than 500 large dunes that exhibit a great diversity of morphologies, ranging from $2 \mathrm{D}$ to $3 \mathrm{D}$ shapes. The largest dune (wavelength over $1000 \mathrm{~m}$ and height over $30 \mathrm{~m}$ ) reaches the maximum size of such sedimentary structures recently described in the Irish Sea, where the tidal regime and depths are quite similar to those of Brittany's continental shelf. The analysis of the entire dune area allows for the establishment of a good height-spacing power-law correlation, but the results do not match the global statistical 
regression compiled by Flemming $(1988,2000)$. The steeper, positive slope of the equation and the outstanding values of the height parameter suggest physically complex dune buildups and require the inclusion of other parameters, such as bedform conditions and the nature of the sediment. Furthermore, no clear relationship has been observed between asymmetry and morphologic parameters, while water depth cannot be considered to be a major controlling factor in the size of dunes.

Concerning dune migration, the new method of spatial cross-correlation and the differential grid performed by subtracting DTMs was applied and validated by controlling for the absence of movement on selected rocky outcrops. Our results allow for the assessment of the vertical sedimentary budget, the direction of horizontal migration and migration rates. They integrate the variability of migration rates along dune crests. Short-terms changes reveal an equilibrate sediment budget over the entire bedform field and the dune crests are accreted, whereas the slopes are eroded. This evolution could be explained by the long evolution of dunes and the action of storm waves rounding sand bedforms, which probably act over the entire depth range. Otherwise, the migration rates calculated for the eastern field of the Banc du Four range from $3 \mathrm{~m} \cdot \mathrm{yr}^{-1}$ to $20 \mathrm{~m} \cdot \mathrm{yr}^{-1}$. Such velocities were never previously mentioned on deep continental shelves $(>70 \mathrm{~m})$ and attest to the, still present, morphodynamic equilibrium of the large dunes. Nevertheless, as previously mentioned regarding the Irish Sea, no power-law relationship equation between dune migration rates and size parameters can be deduced (Van Landeghem et al., 2012). No strong correlation has been established between migration rates and the degree of asymmetry, although this last parameter can be used as a prediction of migration direction. As regards dimension parameters, the asymmetrical evolution depends on the area under study and the migration rates; where the crest lines of dunes are linear and the rates remain below 8-10 m.yr ${ }^{-1}$, the degree of dune asymmetry increases with the migration change, but this tends to be reversed for higher velocities, accompanied by the flexure of dune crests.

Finally, except for the good height-spacing correlation, the lack of clear statistical relationships between other parameters reveals the complexity of the local hydrodynamic 
regime interacting with bedload transport and sedimentary supply. The results relativise the migratory predictions based on periodic geometrical observations. The use of high-resolution bathymetric measurements (MBES), coupled with the high precision motion measurement method (spatial cross-correlation technique), opens the way for new perspectives, particularly for deeper parts of the continental shelf that are poorly characterised. It is clear that these results need to be complemented by new, seasonal data and hydrodynamic measurements along the water column and close to the sea bottom, in order to validate the initial observations and to further constrain the role of storm waves.

\section{Acknowledgements}

This work was funded by the Direction Générale de l'Armement (DGA). The project also benefits from the support of the Labex Mer (ANR-10-LABX-19-01, IUEM, Brest), from the ANR Cocorisco project and from the EU through the FP7 project IQmulus (FP7-ICT-2011-318787). Thaiënne Van Dijk and Katrien Van Landeghem are acknowledged for their careful reviewing and valuable comments. The authors are very grateful to the crews of the vessels "Pourquoi-Pas?" and "Albert Lucas" (Daniel Morigeon and Franck Quéré).

\section{References}

Aliotta, S., Perillo, G.M.E., 1987. A sediment wave field in the entrance to Bahía Blanca estuary, Argentina. Marine Geology 76, 1-14.

Allen, J.R.L., 1968. The nature and origin of bed-form hierarchies. Sedimentology 10, $161-182$

Ashley, G.M., 1990. Classification of large-scale subaqueous bedforms: a new look at an old problem. Journal of Sedimentary Petrology 60, 160-172. 
Barnard, P.L., Hanes, D.M., Rubin, D.M., Kvitek, R.G., 2006. Giant sediment waves at the mouth of San Francisco Bay. EOS Transactions of the American Geophysical Union 87, 285.

Barnard, P.L., Erikson, L., Rubin, D.M., Dartnell, P., Kvitek, R.G. 2012. Analysing bedforms mapped using multibeam sonar to determine regional bedload sediment transport patterns in the San Francisco Bay coastal system. International Association of Sedimentologist special publication 44, 273-294.

Barrie, J.V., Conway, K.W., Picard, K., Greene, H.G., 2009. Large-scale sedimentary bedforms and sediment dynamics on a glaciated tectonic continental shelf: Examples from the Pacific margin of Canada. Continental Shelf Research 29, 796-806.

Berné, S., Castaing, P., Le Drezen, E., Lericolais, G., 1993. Morphology, internal structure, and reversal of asymmetry of large subtidal dunes in the entrance to Gironde estuary (France). Journal of Sedimentary Petrology 63, 780-793.

Besio, G., Blondeaux, P., Brocchini, M., Vittori, G., 2004. On the modeling of sand wave migration. Journal of Geophysical Research, 109.

Besio, G., Blondeaux, P., Vittori, G., 2006. On the formation of sand waves and sand banks. Journal of Fluid Mechanics 557, 1-27.

Best, J., Kostaschuk, R., Hardy, R. 2004. The fluid dynamics of low angle river dunes: Results from integrated field monitoring, laboratory experimentation and numerical modelling. Marine Sandwave and River Dune Dynamics II, University of Twente, Enschede, Netherlands, 17- 23.

Blondeaux P., Vittori, G., 2011. The formation of tidal sand waves: Fully threedimensional versus shallow water approaches. Continental Shelf Research 31, 990-996.

Brown, J., Colling, A., Park, D., Phillips, J., Rothery, D., Wright, J. 1989. Waves, tides and shallow-water processes. The open University, 100.

Buijsman, M.C., Ridderinkhof, H. 2008a. Long-term evolution of sand waves in the Marsdiep inlet. I: High-resolution observations. Continental Shelf Research 28, 1190-1201. 
Buijsman, M.C., Ridderinkhof, H. 2008b. Long-term evolution of sand waves in the Marsdiep inlet. II: Relation to hydrodynamics. Continental Shelf Research 28, 1202-1215.

Caston, V.N.D., Stride, A.H., 1970. Tidal sand movement between some linear sand banks in the North Sea off northeast Norfolk. Marine Geology 9, 38-42.

Dalrymple, R.W., Knight, R.J., Lambiase, J.J., 1978. Bedforms and their hydraulic stability relationships in a tidal environment, Bay of Fundy, Canada. Nature 275, 100-104.

Dehouck, A., 2006. Observations et conditions d'apparition de croissants de plage sur les littoraux de la mer d'Iroise. Norois 201, 7-16.

Delacourt, C., Allemand, P., Casson, B., Vadon, H., 2004. Velocity field of the "La Clapière" landslide measured by the correlation of aerial and Quick-Bird satellite images. Geophysical Research Letters 31, 1-5.

Duffy, G.P., Hughes-Clarke, J.E., 2005. Application of spatial cross correlation to detection of migration of submarine sand dunes. Journal of Geophysical Research 110, 10.1029/2004JF000192.

Dyer, K.R., Huntley, D.A., 1999. The origin, classification and modelling of sand banks and ridges. Continental Shelf Research 19, 1285-1330.

Ernstsen, V.B., Noormets, R., Winter, C., Hebbeln, D., Bartholomä, A., Flemming, B.W., Bartholdy, J., 2006. Quantification of dune dynamics during a tidal cycle in an inlet channel of the Danish Wadden Sea. Geo-Marine Letters 26, 151-163.

Fenster, M.S., FitzGerald, D.M., Moore, M.S., 2006. Assessing decadal-scale changes to a giant sand wave field in eastern Long Island sound. Geology 34, 89-92.

Ferret, Y., Le Bot, S., Tessier, B., Garlan, T., Lafite, R., 2010. Migration and internal architecture of marine dunes in the eastern English Channel over 14 and 56 year intervals: the influence of tides and decennial storms. Earth Surface Processes and Landforms 35, $1480-1493$

Flemming, B.W., 1988. Zur Klassifikation subaquatischer, strömungstransversaler Transportkörper. Bochumer Geologische und Geotechnische Arbeiten 29, 93-97. 
Flemming, B.W., 2000. The role of grain size, water depth and flow velocity as scaling factors controlling the size of subaqueous dunes. A. Trentesaux, T. Garlan (Eds.), Marine Sediment wave Dynamics, Proceedings of and International Workshop held in Lille, France, 23-24 March 2000, University of Lille 1, Lille, 55-60.

Flemming, B.W., Bartholomä, A., 2012. Temporal variability, migration rates and preservation potential of subaqueous dune fields generated in the Agulhas Current on the southeast African continental shelf. International Association of Sedimentologist special publication 44, 229-248.

Francken, F., Wartel, S., Parker, R., Taverniers, E., 2004. Factors influencing subaqueous dunes in the Scheldt Estuary. Geo-Marine Letters 24, 14-24.

Garlan, T., 2004. Apports de la modélisation dans l'étude de la sédimentation marine récente, HDR thesis, Université d'Angers, 158.

Garlan, T., 2007. Study on marine sandwave dynamics. International Hydrographic Review 8, 26-37.

Giardino, A., Van Den Eynde, D., Monbaliu, J., 2010. Wave effects on the morphodynamic evolution of an offshore sand bank. Journal of Coastal Research 51, 127 140

Grochowski, N.T.L., Collins, M.B., Boxall, S.R., Salomon, J.C., 1993. Sediment transport predictions for the English Channel, using numerical models. Journal of the Geological Society 150, 683-695.

Guillou, N., 2007. Rôles de l'hétérogénéité des sédiments de fond et des interactions houle--courant sur l'hydrodynamique et la dynamique sédimentaire en zone subtidale applications en Manche orientale et à la pointe de la Bretagne. PhD thesis, Université de Bretagne Occidentale, 469.

Hinschberger, F., 1962. Résultats de 14 stations hydrologiques dans l'Iroise et à ses abords. Comptes Rendus de l'Académie des sciences 255, 2629-2631.

Hinschberger, F., 1970. L'Iroise et les abords d'Ouessant et de Sein. PhD thesis, Université de Caen, 302. 
Hoffman, T.J., 2005. The influence of sea level rise on sandbank morphodynamics : a sensitivity analysis.

Houbolt, J.H.C., 1968. Recent sediments in the southern Bight of the North Sea. Geologie en Mijnbouw 47, 245-273.

Hulscher, S.J.M.H., 1996. Tidal-induced large-scale regular bed fonn patterns in a three-dimensional shallow water model. Journal of Geophysical Research 101, 727-744

Hulscher, S.J.M.H., Van Den Brink, G.M., 2001. Comparison between predicted and observed sand waves and sand banks in the North Sea. Journal of Geophysical Research 106, 9327-9338.

Hulscher, S.J.M.H., Dohmen-Janssen, C.M., 2005. Introduction to special section on marine sand wave and river dune dynamics. Journal of Geophysical Research 110, 6.

Huthnance, J.M., 1973. Tidal currents asymmetries over the Norfolk sandbanks. Journal of Estuarine and Coastal Marine Science 1, 89-99.

Kenyon, N.H., Cooper, W., 2004. Sand banks, sand transport and offshore wind farms. Report for DTI.

Kleinhans M., 2004. Sorting in grain flows at the lee side of dunes. Earth-Science Reviews 65, 75-102.

Knaapen, M.A.F., 2005. Measuring sand wave migration in the field. Comparison of different data sources and an error analysis. Journal of Geophysical Research 110, 152-159.

Knaapen, M.A.F., 2009. Sandbank occurrence on the Dutch continental shelf in the North Sea. Geo-Marine Letters 29, 17-24.

Kubicki, A., 2008. Large and very large subaqueous dunes on the continental shelf off southern Vietnam, South China Sea. Geo-Marine Letters 28, 229-238.

Lapierre F., Bouysse P., 1975.Carte géologique de la marge continentale française à l'échelle du 1/250000 Ouessant (I-Géologie et Structure), Edition du B.R.G.M.

Le Bot, S., Trentesaux, A., Garlan, T., Berné, S., Chamley, H., 2000. Influence des tempêtes sur la mobilité des dunes tidales dans le détroit du Pas-de-calais. Oceanologica Acta $23,129-141$. 
Le Bot, S., 2001. Morphodynamique de dunes sous-marines sous influence des marées et des tempêtes. Processus hydro-sédimentaires et enregistrement. Exemple du Pas-de-Calais. PhD thesis, Université de Lille 1, 300.

Le Bot, S., Trentesaux, A., 2004. Types of internal structure and external morphology of submarine dunes under the influence of tide- and wind-driven processes (Dover Strait, northern France). Marine Geology 211, 143-168.

Le Bot, S., Idier, D., Augris, C., Garlan, T., Guennoc, P., Harrison, M., James, C., Philpott, S., Trentesaux, A., Vinchon, C., Fournier, M., 2006. Stability fields for bedforms of the continental shelves : determination of discriminant environmental parameters. Example of the Dover Strait. 17th International Sedimentological Congress, ISC 2006, Fukuoka, Japan

McCave, L.N., 1971. Sand waves in the North Sea of the Coast of Holland. Marine Geology 10, 199-225.

McCave, L.N., Langhorne, N., 1982. Sand waves and sediment transport around the end of a tidal sandbank. Sedimentology 29, 95-110.

Neill, S.P., Scourse, J.D., 2009. The formation of headland/island sandbanks. Continental Shelf Research 29, 2167-2177.

Németh, A.A., Hulscher, S.J.M.H., Van Damme, R.M.J., 2007. Modelling offshore sand wave evolution. Continental Shelf Research 27, 713-728

Pattiaratchi, C.B., Collins, M.B., 1987. Mechanisms for linear sandbank formation and maintenance in relation to dynamical oceanographic observations. Progress in Oceanography 19, 117-176.

Porter-Smith, R., Harris, P.T., Andersen, O.B., Coleman, R., Greenslade, D., Jenkins, C.J., 2004. Classification of the Australian continental shelf based on predicted sediment threshold exceedance from tidal currents and swell waves. Marine Geology 211, 1-20.

Reynaud, J.Y., Tessier, B., Proust, J.N., Dalrymple, R., Marsset, T., DeBatist, M., Bourillet, J.F., Lericolais, G., 1999. Eustatic and hydrodynamic controls on the architecture of a deep shelf sand bank (Celtic Sea). Sedimentology 46, 703-721. 
Reynaud, J.Y., Tessier, B., Auffret, J.-P., Berné, S., De Batist, M., Marsset, T. et Walker, P., 2003. The offshore Quaternary sediment bodies of the English Channel and its Western approaches. Journal of Quaternary Science 18, 361-371.

Schmitt, T., Mitchell N.C., Ramsay, A.T.S., 2008. Characterizing uncertainties for quantifying bathymetry change between time-separated multibeam echo-sounder surveys. Continental Shelf Research 28, 1166-1176.

Sentchev, A., Forget, P., Barbin, Y., Yaremchuk, M., 2011. Surface circulation in the Iroise Sea (W. Brittany) from high resolution HF radar mapping. Journal of Marine Systems 109-110, 153-168.

Stride, A.H., 1963. North-east trending ridges of the Celtic Sea. Proceedings of the Ussher Society 1, 62-63.

Tobias, C.J., 1989. Morphology of sandwaves in relation to current, sediment and wave data along the Eurogeul, North Sea. Report GEOPRO 01, Department of Physical Geography, University of Utrecht, The Netherlands.

Trentesaux, A., Stolk, A., Berné, S., 1999. Sedimentology and stratigraphy of a tidal sand bank in the southern North Sea. Marine Geology 159 253-272.

Van Dijk, T.A.G.P., Kleinhans, M.G., 2005. Processes controlling the dynamics of compound sandwaves in the North Sea, Netherlands. Journal of Geophysical Research 110, 15.

Van Dijk, T.A.G.P., Lindenbergh, R.C., Egberts, P.J.P., 2008. Separating bathymetric data representing multiscale rhythmic bed forms: A geostatistical and spectral method compared. Journal of Geophysical Research 113, F04017.

Van Landeghem, K.J.J., Uehara, K., Wheeler, A.J., Mitchell, N.C., Scourse, J.D., 2009a. Post-glacial sediment dynamics in the Irish Sea and sandwave morphology: datamodel comparisons. Continental Shelf Research 29, 1723-1736

Van Landeghem, K.J.J., Uehara, K., Wheeler, A.J., Mitchell, N.C., Scourse, J.D., 2009b. Post-glacial sediment dynamics in the Irish Sea and sediment wave morphology : Data-model comparisons. Continental Shelf Research 29, 1723-1736. 
Van Landeghem, K.J.J., Baas, J.H., Mitchell, N.C., Wilcockson, D., Wheeler, A.J., 2012. Reversed sandwave migration in the Irish Sea, NW Europe: A reappraisal of the validity of geometry-based predictive modelling and assumptions. Marine Geology 295-298, $95-112$.

Van Oyen, T., Blondeaux, P., 2009. Grain sorting effects on the formation of tidal sand waves. Journal of Fluid Mechanics 629, 311-342.

Van Santen, R.B., De Swart, H.E., Van Dijk, T.A.G.P., 2011. Sensitivity of tidal sand wavelength to environmental parameters : A combined data analysis and modelling approach. Continental Shelf Research 31, 966-978.

Van Rijn, L.C., 1984. Sediment transport, part II: suspended load transport. Journal of Hydraulic Engineering 110, 1613-1641.

Venditti, J.G., Church, M., Bennett, S.J., 2005. On the transition between 2D and 3D dunes. Sedimentology 52, 1343-1359.

Weill, P., Mouazé, M., Tessier, B., Brun-Cottan, J.C., 2010. Hydrodynamic behaviour of coarse bioclastic sand from shelly cheniers. Earth Surface Processes and Landforms 35, 1642-1654.

Xu, J.P., Wong, F.L., Kvitek, R., Smith, D.P., Paull, C.K., 2008. Sediment wave migration in Monterey Submarine Canyon, Central California. Marine Geology 248, 193-212

Yalin, M.S., 1964. Geometrical properties of sand waves. Journal of the Hydraulics 90, 105-119.

Yalin, M.S., 1977. Mechanics of Sediment Transport. Pergamon Press New York, 298. Zhen Xia, L., Dong Xing, X., Berné, S., Kui Yang, W., Marsset, T., Yu Xiang, T., Bourillet, J.F., 1998. Tidal deposition systems of China's continental shelf, with special reference to the eastern Bohai Sea. Marine Geology 145, 225-253. 

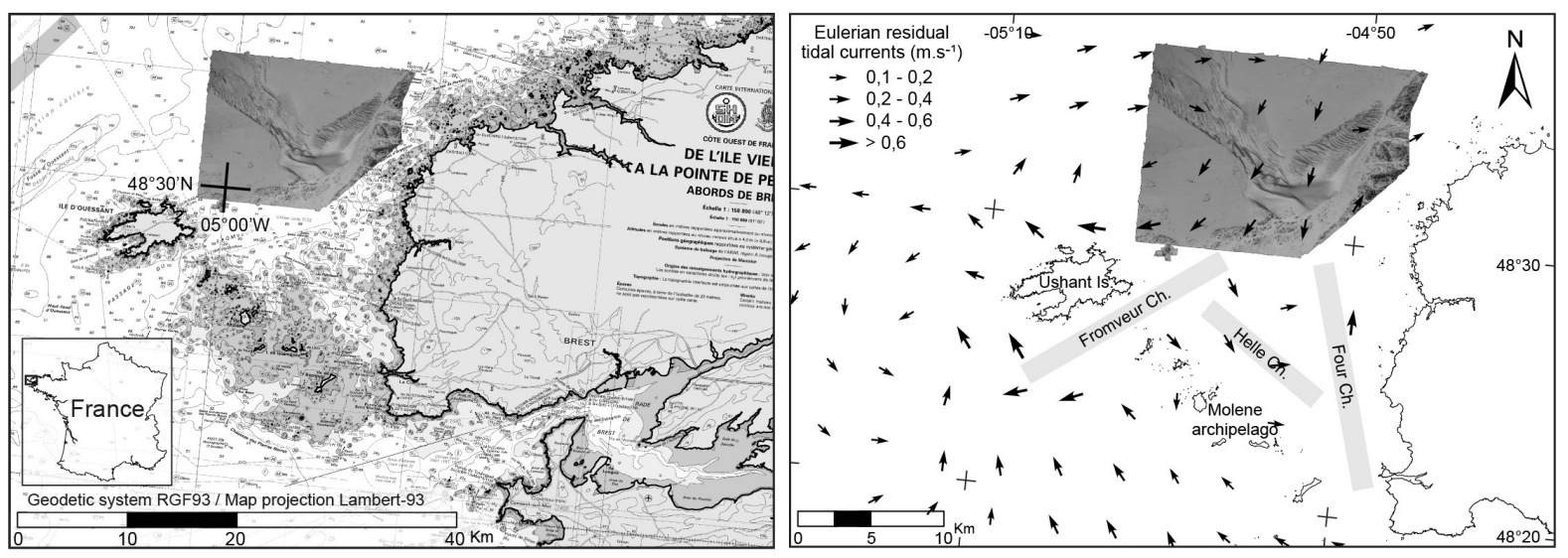

Figure 1: (left) Map of the Iroise Sea (situated between Brittany French coast and the Ushant-Molene Archipelago) showing the location of DTM EvalHydro2009. The study area covers $14 \times 18 \mathrm{~km}^{2}$ with the water depth ranging up to $100 \mathrm{~m}$. (right) Eulerian residual tidal currents according to PREVIMER for a tide range of 90 .

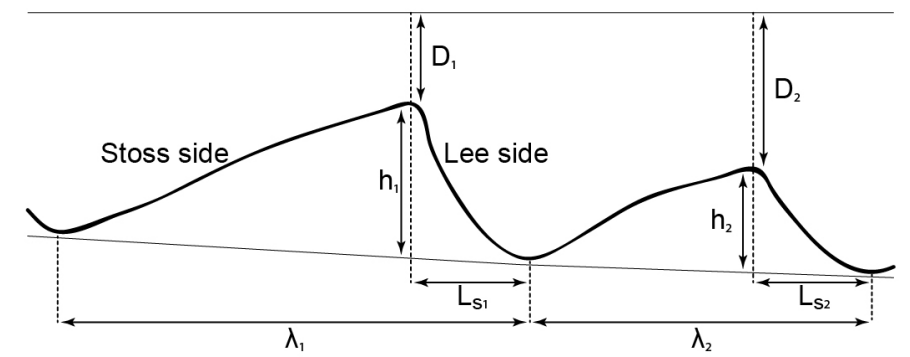

Figure 2 : Schematic representation of 1 and 2 dunes characteristics. $\lambda$ is the wavelength, $L_{s}$ is the lee side length, $h$ is the height and $D$ is the crest depth.
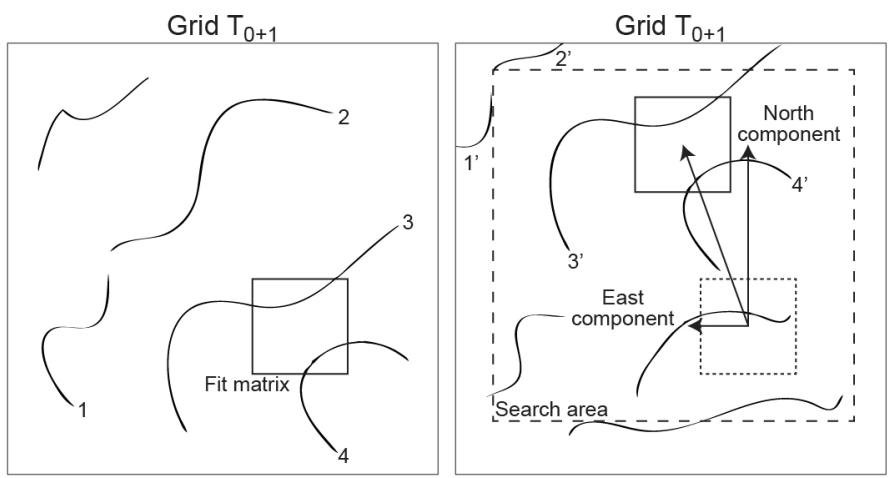

Figure 3 : Schematic representation of the cross-correlation technique to obtain the displacement field. For every grid point, a fit matrix for $\mathrm{DTM}_{\mathrm{t} 1}$ defined at the moment $\mathrm{t} 1$ is shifted in east and north directions within a search matrix for $\mathrm{DTM}_{\mathrm{t} 2}$ defined at the moment $\mathrm{t} 2$. The search radius is defined from maximum assumed value of migration. 


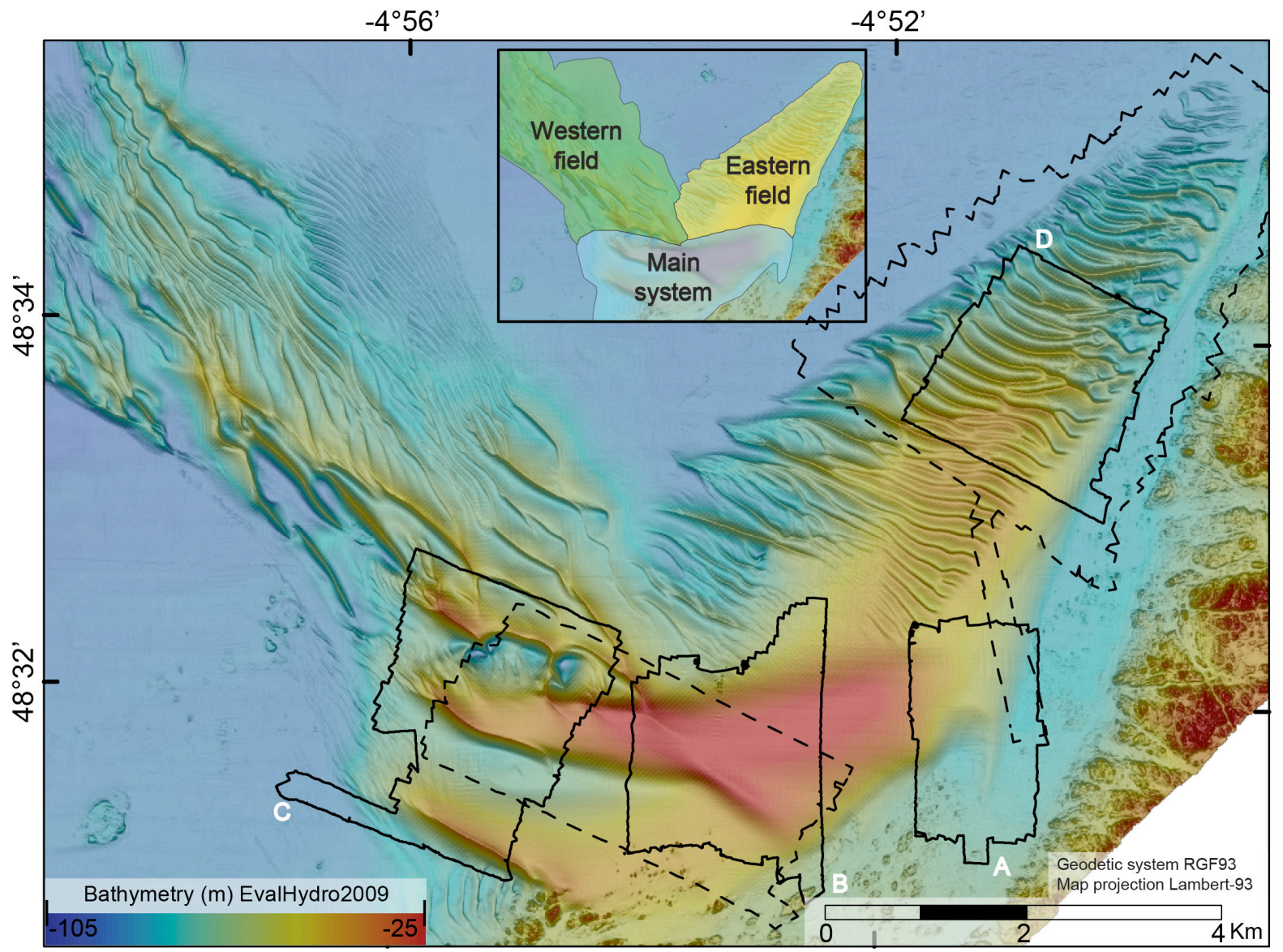

Figure 4 : Bathymetry of Banc du Four on February 2009 defined with a $5 \mathrm{~m}$ resolution. Areas of AlbertGeo2010 swath surveys are outlined by black solid lines and labelled in white as $A, B, C$ and D. Areas of AlbertGeo2011 swath surveys are outlined by black dotted line.
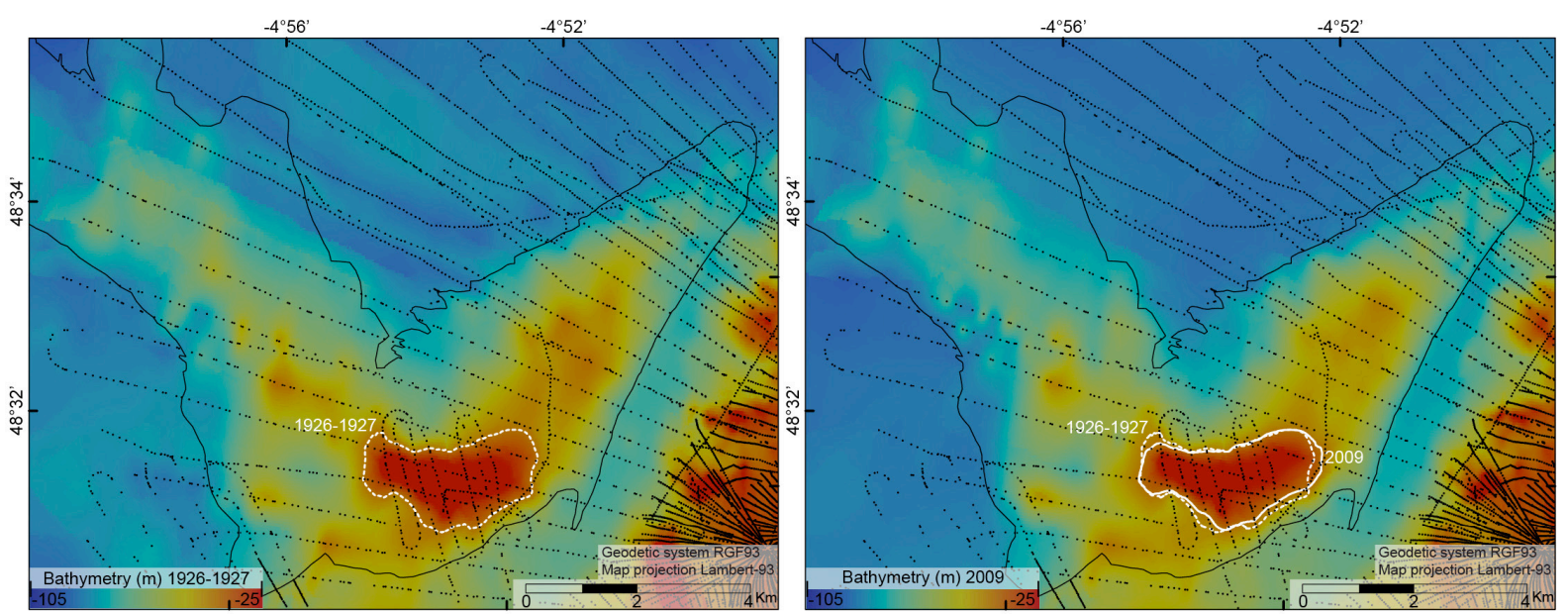

Figure 5 : (left) Bathymetry of Banc du Four on 1926-1927 performed by Kriging interpolation of depth sounding. (right) Bathymetry of Banc du Four on 2009 performed by Kriging interpolation using the same 1926-1927 sounding with depth measurement values of 2009 . The outer limits of the Banc du Four is in black solid line, the sounding points are in black dots, the isobath $50 \mathrm{~m}$ representative of the sandbank shape is in white solid line (2009) and in white dotted line (1926-1927). 


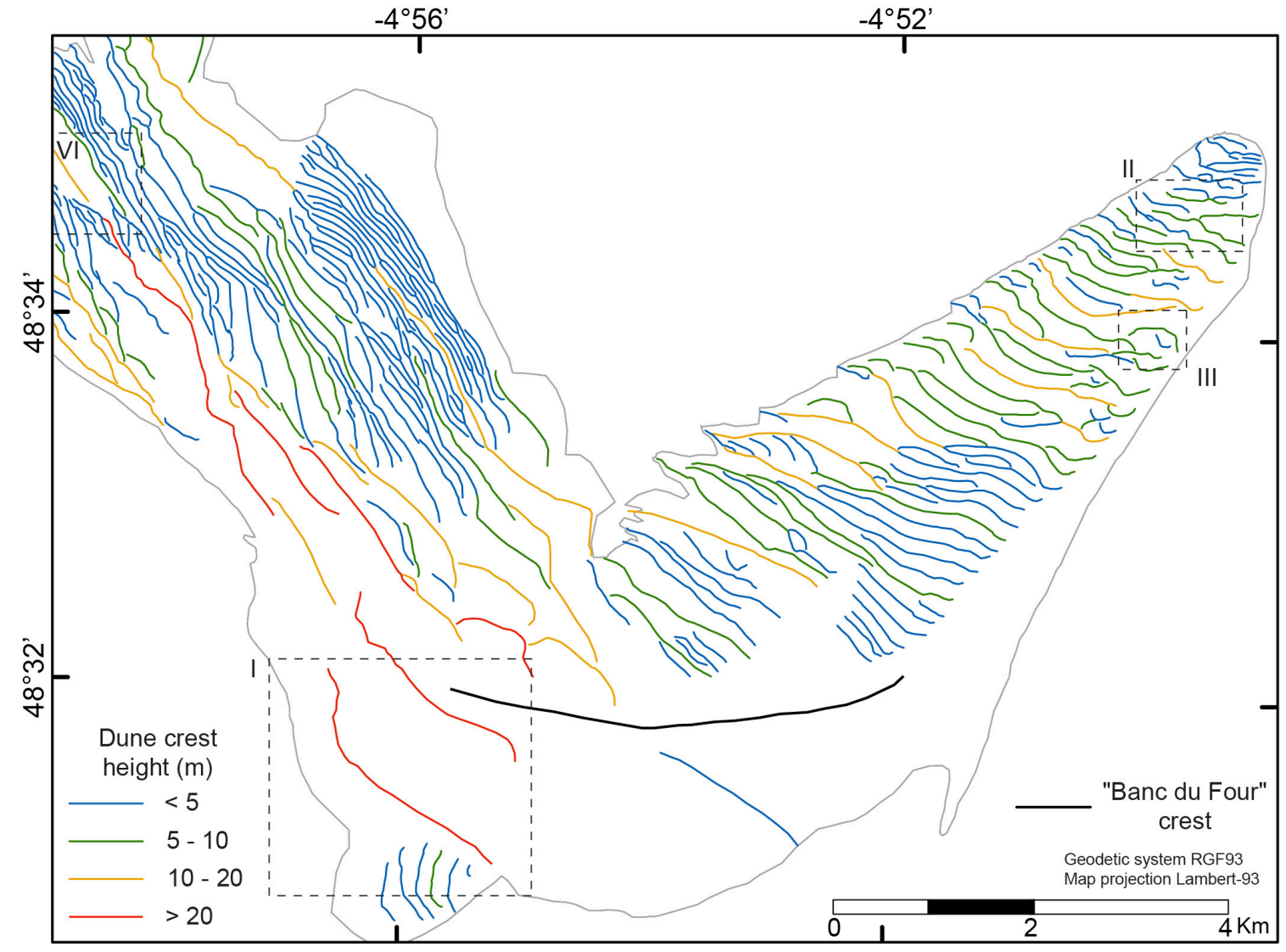

Figure 6 : Map specifying crest heights of the dunes. Note that dunes higher than $20 \mathrm{~m}$ have $\lambda$ greater than $500 \mathrm{~m}$.
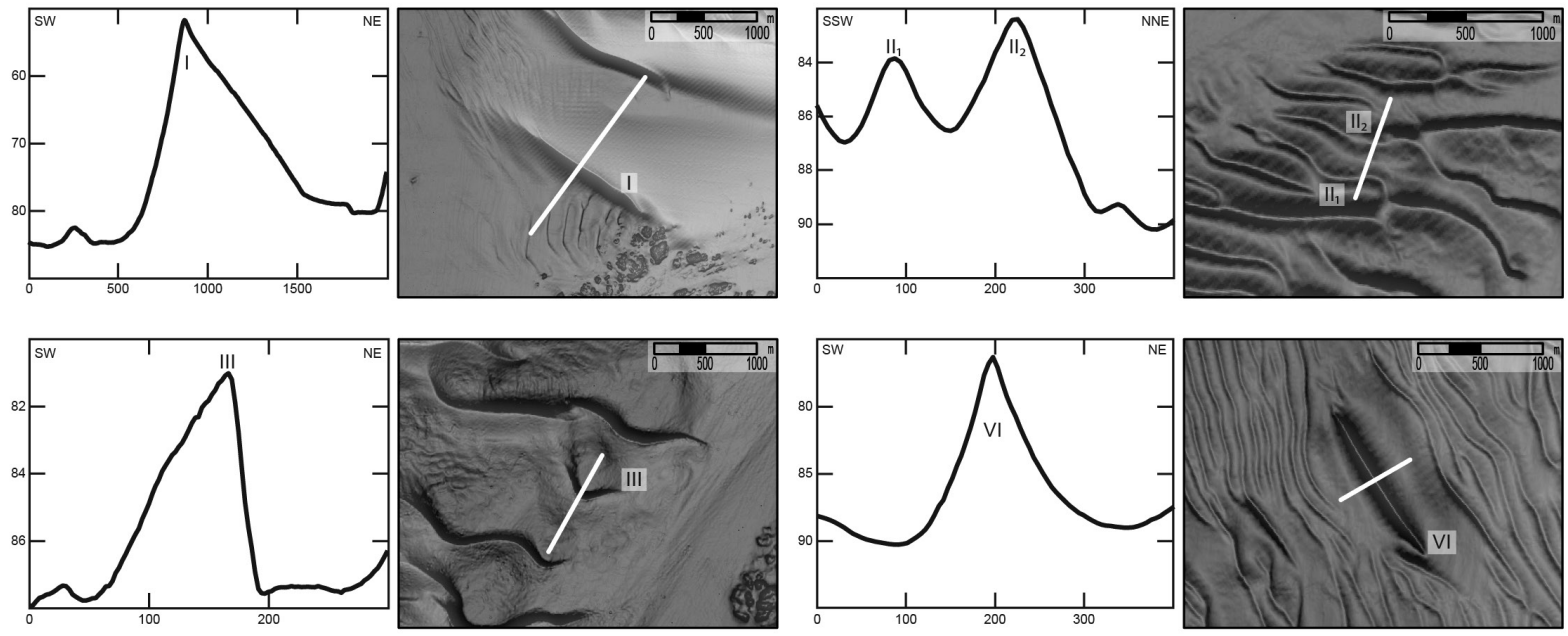

Figure 7 : Examples of different shapes of dunes observed in the "Band du Four": (upper left corner) giant asymmetrical straight dune, (upper right corner) slightly to sinuous dunes with reversed polarity, (lower left corner) barchans morphology and (lower right corner) trochoidal morphology dune. 


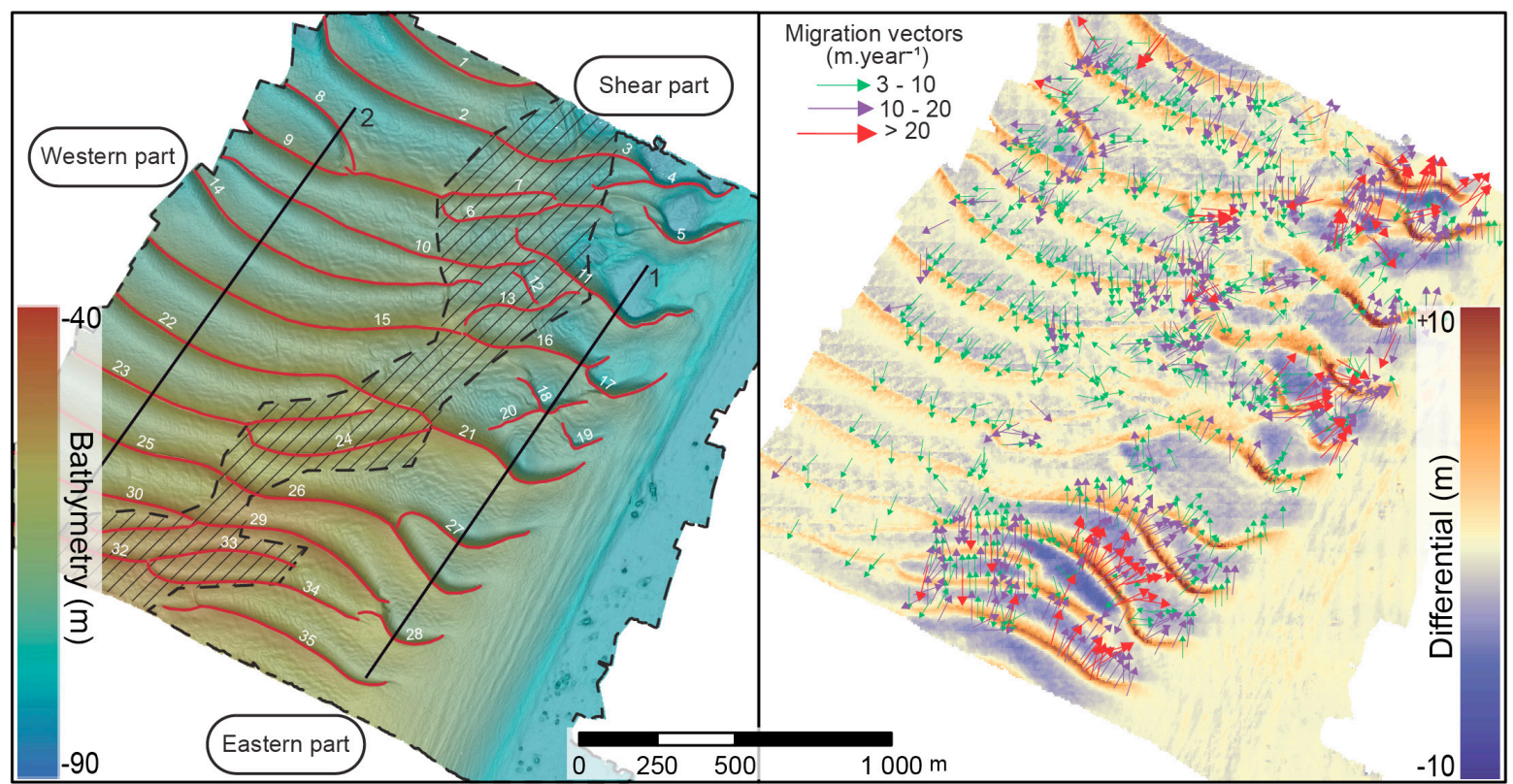

Figure 8 : (left) Bathymetry of $\mathrm{D}$ zone on August 2010 with a $2 \mathrm{~m}$ resolution. The two bathymetric profiles are located in black. (right) Bathymetry differential between 2009 and 2010 with the migration vectors obtained with the spatial cross-correlation technique.

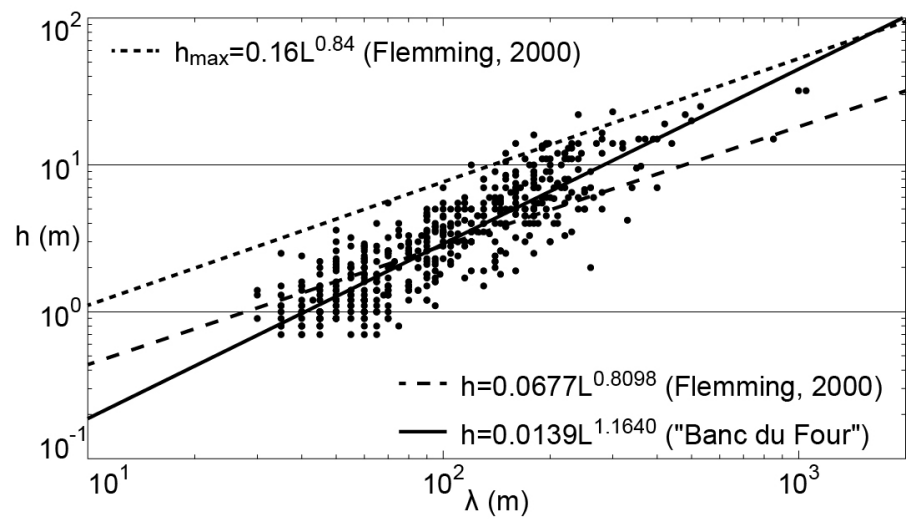

Figure 9 : Crest height as a function of the wavelength of dunes measured across the Banc $d u$ Four area with the corresponding linear regression fit indicated by the solid line. For comparison, two dotted lines indicate equilibrium equation and upper limit predicted by the study of Flemming (2000). 


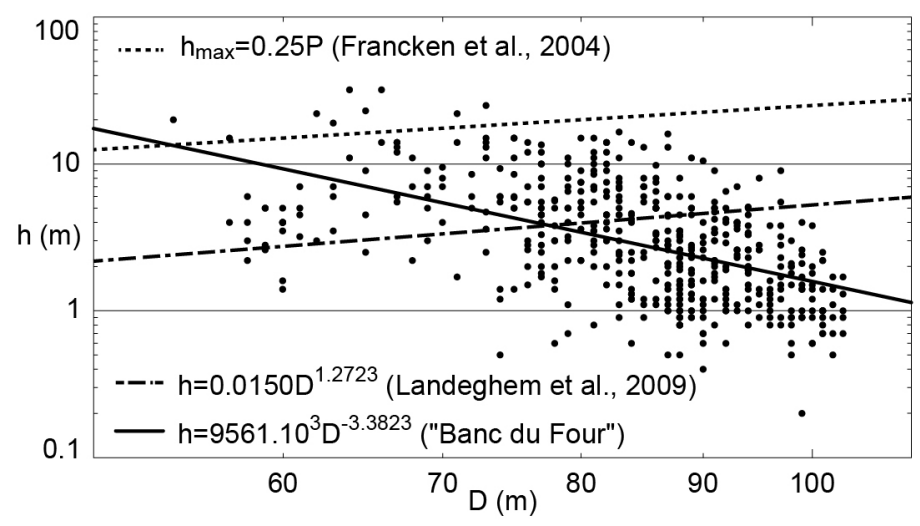

Figure 10 : The crest height as a function of the depth crest. The solid line indicates the observed statistical correlations between $\mathrm{h}$ and $\mathrm{D}$. For comparison, the statistical correlations reported by other authors are shown.

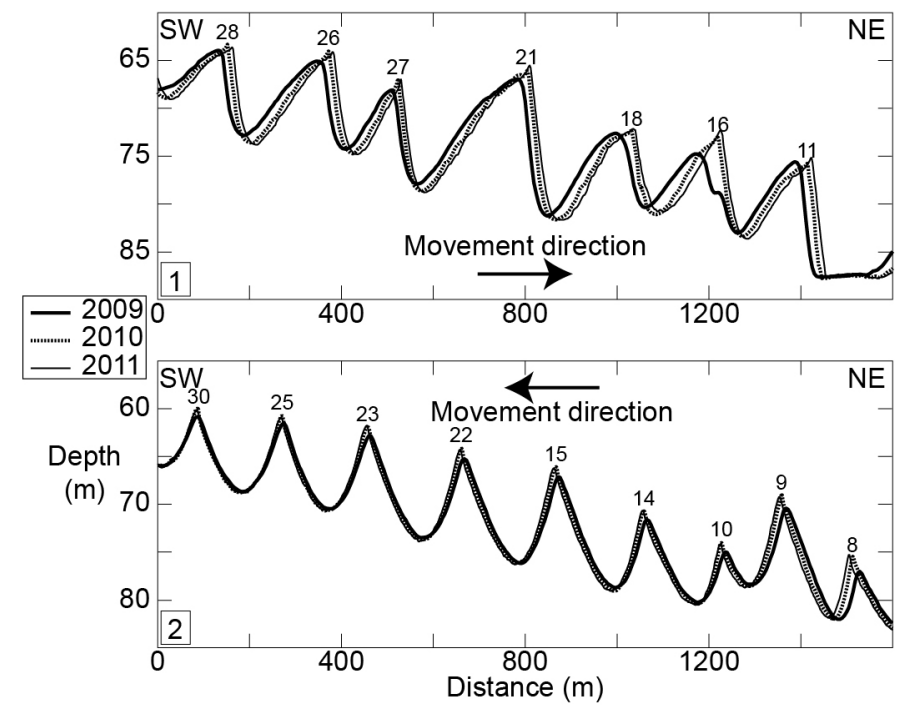

Figure 11 : Bathymetry profiles 1 and 2 of ZoneD (location in Fig. 8). Crests numerous are the same than Figure 8. 


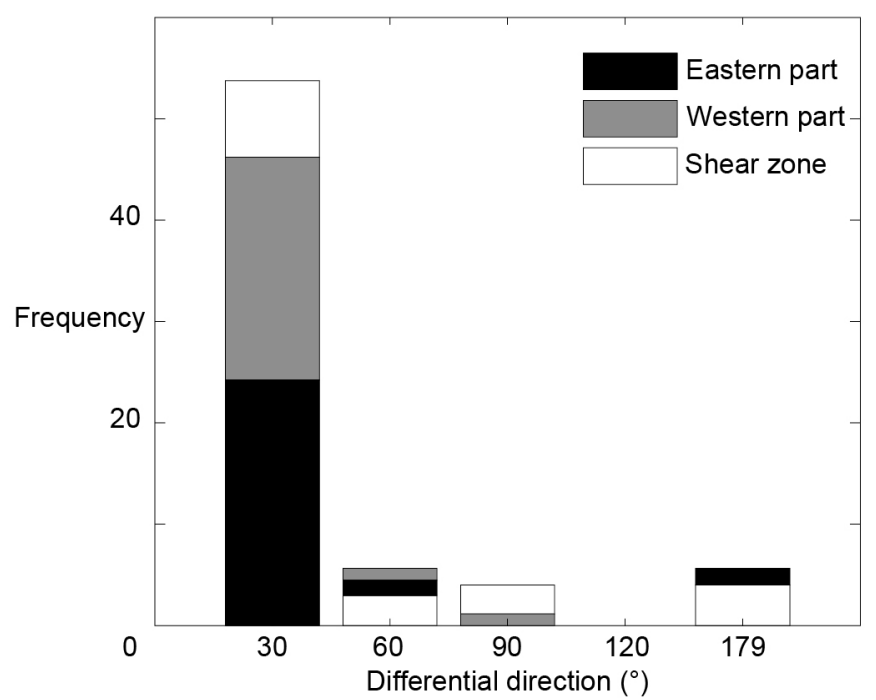

Figure 12 : Frequency distribution of differential direction values (morphological dune directions minus migration dune directions) on ZoneD.

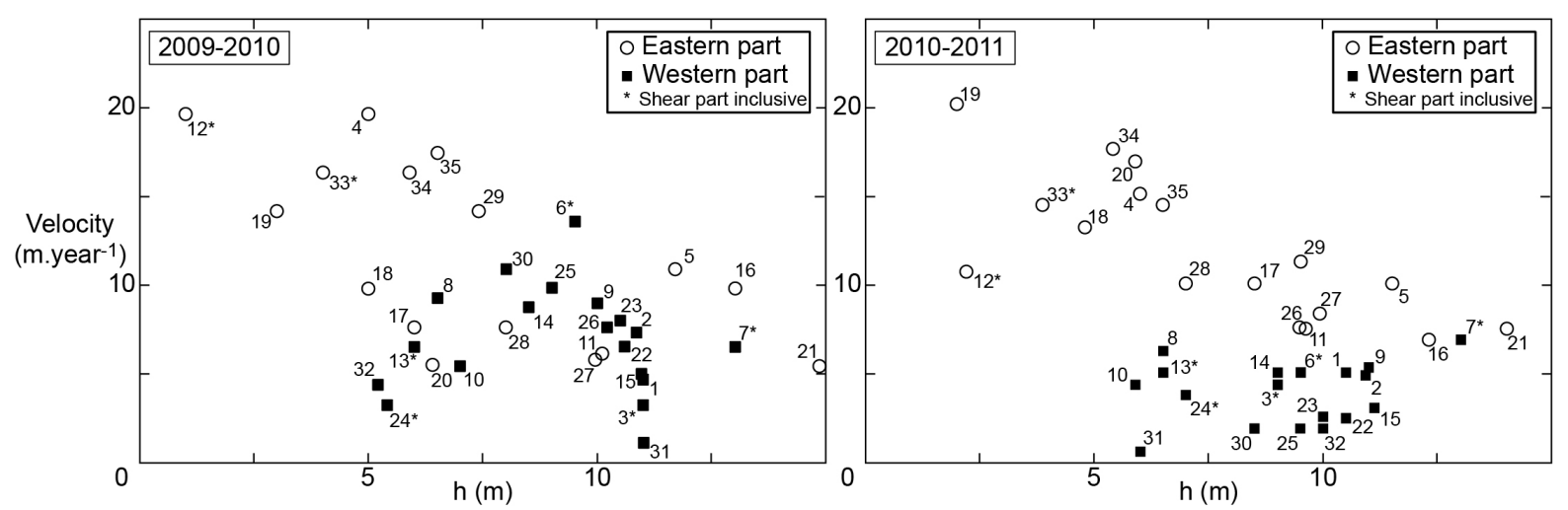

Figure 13 : The height $(\mathrm{h})$ as a function of the migration velocity measured on ZoneD's dunes between (left) 2009-2010 and (right) 2010-2011.

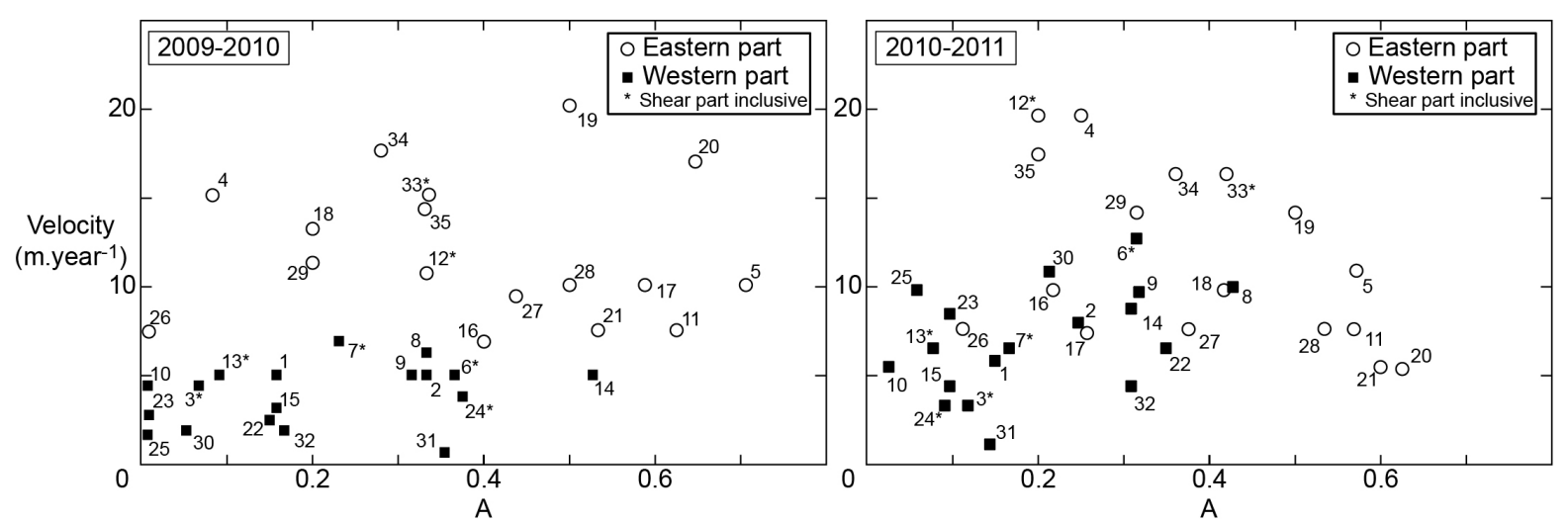

Figure 14 : The asymmetry $(A)$ as a function of the migration velocity measured on ZoneD's dunes between (left) 2009-2010 and (right) 2010-2011. 


\begin{tabular}{|c|c|c|}
\hline Survey, dates, vessel & Acquisition system & DTM \\
\hline $\begin{array}{l}\text { EvalHydro2009 } \\
\text { 16th to } 27 \text { th February } 2009 \\
\text { R/V "Pourquoi-Pas?" }\end{array}$ & 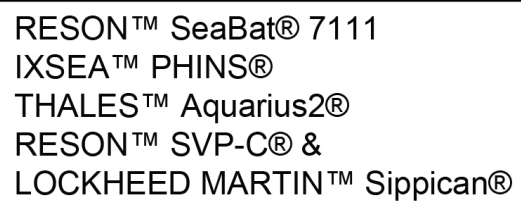 & $\begin{array}{l}0.005 \mathrm{~m} \text { horizontal precision } \\
0.01 \mathrm{~m} \text { vertical precision } \\
5 \mathrm{~m} \text { horizontal resolution }\end{array}$ \\
\hline $\begin{array}{l}\text { AlbertGeo2010 and AlbertGeo2011 } \\
\text { 27th August to 2nd September } 2010 \\
\text { 20th to 29th July } 2011 \\
\text { R/V "Albert Lucas" }\end{array}$ & 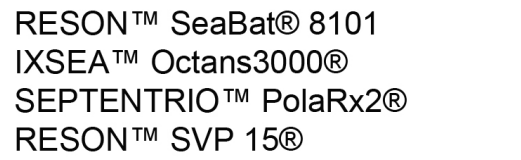 & $\begin{array}{l}0.01 \mathrm{~m} \text { horizontal precision } \\
0.02 \mathrm{~m} \text { vertical precision } \\
2 \mathrm{~m} \text { horizontal resolution }\end{array}$ \\
\hline
\end{tabular}

Table 1 : Configurations of surveys EvalHydro2099 and AlbertGeo2011. 